\title{
Marketed drugs used for the management of hypercholesterolemia as anticancer armament
}

This article was published in the following Dove Press journal:

OncoTargets and Therapy

8 September 2017

Number of times this article has been viewed

\author{
Panagiota Papanagnou' \\ Theodora Stivarou ${ }^{2}$ \\ loannis Papageorgiou' \\ Georgios E Papadopoulos ${ }^{3}$ \\ Anastasios Pappas' \\ 'Department of Urology, Agios \\ Savvas Cancer Hospital, Athens, \\ Greece; ${ }^{2}$ Immunology Laboratory, \\ Immunology Department, Hellenic \\ Pasteur Institute, Athens, Greece; \\ ${ }^{3}$ Department of Biochemistry and \\ Biotechnology, University of Thessaly, \\ Larissa, Greece
}

\begin{abstract}
The design of novel pharmacologic agents as well as their approval for sale in markets all over the world is a tedious and pricey process. Inevitably, oncologic patients commonly experience unwanted effects of new anticancer drugs, while the acquisition of clinical experience for these drugs is largely based on doctor-patient partnership which is not always effective. The repositioning of marketed non-antineoplastic drugs that hopefully exhibit anticancer properties into the field of oncology is a challenging option that gains ground and attracts preclinical and clinical research in an effort to override all these hindrances and minimize the risk for reduced efficacy and/or personalized toxicity. This review aims to present the anticancer properties of drugs used for the management of hypercholesterolemia. A global view of the antitumorigenicity of all marketed antihypercholesterolemic drugs is of major importance, given that atherosclerosis, which is etiologically linked to hypercholesterolemia, is a leading worldwide cause of morbidity and mortality, while hypercholesterolemia and tumorigenesis are known to be interrelated. In vitro, in vivo and clinical literature data accumulated so far outline the mechanistic basis of the antitumor function of these agents and how they could find application at the clinical setting.
\end{abstract}

Keywords: antihypercholesterolemic agents, cancer, synergism, repurposing

\section{Introduction}

Many pharmacologic agents that are commercially available find application in multiple fields in everyday clinical practice. Characteristically, the chemotherapeutic agent mitomycin C exhibits multilevel therapeutic exploitability functioning, both for killing cancer cells and regulating wound healing. ${ }^{1,2}$ Importantly, a growing body of evidence suggests that several pharmacologic agents could be "repositioned" or "repurposed" in the field of oncology, owing to their interference with signaling pathways which are crucial for tumorigenesis. This notion is experimentally (at the preclinical level, clinical level or even at both levels) corroborated for marketed agents currently used for the management of different pathologic entities ranging from pain, ${ }^{3}$ gastrointestinal disorders, ${ }^{4}$ depression, ${ }^{5}$ hypercholesterolemia ${ }^{6}$ and diabetes mellitus type $\mathrm{II}^{7,8}$ to human immunodeficiency virus ${ }^{9,10}$ and parasitic infection. ${ }^{11,12}$

Herein, for the first time, we concurrently review the antitumor activity of the widely prescribed marketed antihypercholesterolemic drugs, statins and ezetimibe. Notably, although a concernable amount of theoretical evidence regarding the anticancer activity of statins in different types of malignancies has already been published, ${ }^{13,14}$ to the best of our knowledge, so far, there has been no published work summarizing the anticancer function of both statins and ezetimibe. The fact that hypercholesterolemia is etiologically linked to a leading cause of morbidity and mortality worldwide, that is, atherosclerosis ${ }^{15}$
Correspondence: Panagiota Papanagnou Department of Urology, Agios Savvas Cancer Hospital, I7I Alexandra's Avenue, GR-II522, Athens, Greece Tel +302107718060

Email panagiota1983rr@yahoo.com 
and that high blood cholesterol levels are interrelated with tumorigenesis ${ }^{16}$ underlines the impetus for presenting the antitumorigenicity of this category of drugs. Bile acid sequestrants (cholestyramine, colestipol and colesevelam) are also used for the management of hypercholesterolemia. Yet, to the best of our knowledge, no evidence has been provided so far suggesting any anticancer activity for these drugs. The objective of this article is to prompt further basic and/or clinical research regarding the repositioning of the aforementioned or other marketed drugs in cancer therapeutics by presenting the antitumorigenicity of non-vitamin antilipidemic agents that are either synthetic (atorvastatin, fluvastatin, rosuvastatin and ezetimibe) or fermentation derived (lovastatin, simvastatin and pravastatin). Of note, vitamin B3 (niacin), which is known to reduce low-density lipoprotein (LDL)-cholesterol levels, ${ }^{17}$ participates to antitumor pathways upon its in vivo conversion into nicotinamide. ${ }^{18,19}$ However, only the antitumor functions of non-vitamin antilipidemic are presented here.

\section{Current clinical use of statins and ezetimibe}

Statins are LDL-cholesterol-lowering agents. They serve as 5-hydroxy-3-methylglutaryl-coenzyme A (HMG-CoA) reductase inhibitors, thereby blocking the rate-limiting step in mevalonate metabolic pathway, which is responsible for the biosynthesis of cholesterol and isoprenoids, exemplified by geranylgeranyl pyrophosphate (GGPP). ${ }^{20}$ Statins are currently commonly prescribed both to prevent the onset of cardiovascular disease (CVD) as well as to patients who already suffer from CVD, since in the latter case, they reduce the mortality rates. ${ }^{21}$

Like statins, ezetimibe is an LDL-cholesterol-lowering drug. Yet, it works through a different mechanism to prevent the exogenous uptake of cholesterol as well as its biliary absorption. Hence, until now, ezetimibe finds clinical application as an antihypercholesterolemic agent..$^{22,23}$ It is used as a second-line option in hypercholesterolemic individuals who do not satisfactorily respond to statin therapy, either alone or in combination with a statin.

\section{Possible therapeutic repurposing Overview}

Hypercholesterolemia has been associated with accelerated tumor growth, ${ }^{16}$ while statins interfere with the pathways modulating molecules that are crucial for tumorigenesis; the fact that prenylation of the cancer-associated G-protein superfamily members (eg, RAS isoforms and RhoA) is required for their activation ${ }^{20}$ has instigated researchers to explore the antitumor activity of statins. Although there are many reports indicating that the anticancer function(s) of statins can be reversed by mevalonate pathway intermediates, ${ }^{24,25}$ it becomes increasingly clear that statins may actually employ far more sophisticated mechanism of action to affect tumor biology. ${ }^{26-30}$

In striking contrast to statins which have long been known to target oncoproteins (eg, RAS), ezetimibe targets a molecule that is not an oncoprotein. In fact, ezetimibe blocks the intestinal sterol influx transporter NiemannPick C1-Like 1 (NPC1L1). ${ }^{22}$ To the best of our knowledge, however, no evidence has been provided that ezetimibe's anticancer mechanism of action is NPC1L1-dependent. As it is presented immediately below, ezetimibe's function goes beyond NPC1L1 regulation to interfere with tumor microvascularization, ${ }^{22}$ as well. These data underline the fact that the pharmacologic agents that either target the oncoproteins or interfere with different pathways that involve cancer-associated proteins merit research interest as possible anticancer drugs.

\section{Preclinical data}

\section{Simvastatin, pravastatin and rosuvastatin}

Simvastatin exerts antiproliferative effects on non-small cell lung cancer (NSCLC) A549 cells by impairing the activation of ERK. ${ }^{25,31}$ These effects are counteracted by fueling the mevalonate pathway with the terpenoid precursor, farnesyl pyrophosphate. ${ }^{25}$ Downregulation of transforming growth factor- $\beta$ receptor II (TGF- $\beta$ RII) has also been documented as a molecular event that is associated with simvastatindependent inhibition of ERK. ${ }^{25}$ This is of major importance, since deregulated TGF- $\beta$ signaling is a well-known culprit in lung carcinogenesis. ${ }^{32}$ Other mechanism linked to the simvastatin-mediated deterioration of NSCLC cell viability is the pro-oxidant activity of this $\operatorname{drug}^{33}$ as well as its ability to decrease the expression of antiapoptotic proteins (XIAP, $\mathrm{Bcl}-2$ ) and to stimulate the expression of proapoptotic ones, including Bax and p53. ${ }^{31,34}$ Moreover, simvastatin acts in a cytostatic fashion through negating the expression of cell cycle-regulatory molecules (cyclin D1, cyclin-dependent kinase 4 [CDK4]) governing the G1/S phase transition in NSCLC A549 and NCI-H460 cells. ${ }^{34,35}$ Importantly, experiments indicate that treatment of different cancer cell lines with simvastatin regulates $\mathrm{Bcl}-2 / \mathrm{Bax}$ expression and triggers apoptosis, but leaves the human normal small airway epithelial cells unaffected. ${ }^{36}$

In highly metastatic triple-negative MDA-MB-231 breast cancer cells, simvastatin functions in an antigrowth manner 
to inhibit NFkB/PTEN- and NFkB/Bcl ${ }_{\mathrm{XL}}$-dependent routes. ${ }^{37}$ Also, the metastatic potency of these cells is antagonized by simvastatin or lovastatin that upregulate the expression of p53 which, in turn, represses the expression of the adhesion molecule, CD $44 .{ }^{38}$ Another mechanism by which simvastatin decreases the migratory and invasive potential of these cells is by interfering with a Rho GTPase/Hippo-YAP pathway, which modulates the expression of the oncogenic protein CD168 (hyaluronan-mediated motility receptor) whose gene promoter is responsive to the transcription coactivator YAP and TEAD family transcription factors. ${ }^{39}$ In breast cancer cells which are positive for HER2, simvastatin seems to be a promising anticancer agent that shuts off the expression of HER2 through upregulating its negative transcriptional modulator, namely, PEA3. ${ }^{24}$ In MCF-7 breast cancer cells (these cells are ER-positive and HER2-negative), simvastatin and fluvastatin stimulate apoptosis through positively modulating the expression of inducible nitric oxide synthase (iNOS) at the transcriptional level. ${ }^{40}$ In ER-negative breast cancer cells, simvastatin displays synergistic antigrowth function with the cardiac glycoside, digitoxin. ${ }^{41}$

Experimental evidence pinpoints to an interrelation between the retinoblastoma protein (RB) status and the tamoxifen resistance phenotype. In fact, analyses have shown that in a molecular background where the tumor-suppressive retinoblastoma protein $(\mathrm{pRb})$ axis is dysfunctional (eg, in $\mathrm{SaOS} 2$ osteosarcoma cells), the interference with the assembly of the minichromosome maintenance (MCM) complex and DNA replication causes more extensive DNA damages than in the presence of functional pRb (eg, in U2OS osteosarcoma cells). ${ }^{42}$ Besides, premenopausal ER-positive breast cancer patients carrying a functional $\mathrm{pRb}$ are benefited from adjuvant tamoxifen treatment, in striking contrast to premenopausal ER-positive breast cancer patients with nonfunctional $\mathrm{pRb}$, who do not experience any benefit. ${ }^{43}$ Simvastatin negatively affects MCM7 expression, resulting in the elevation of the DNA damage marker, $\gamma \mathrm{H} 2 \mathrm{AX}$. Remarkably, the combined treatment of tamoxifen-resistant human breast cancer cells (these cells express $\mathrm{pRb}$ at lower levels in comparison to their wild-type counterparts) with simvastatin and tamoxifen evokes a genotoxic signal, which is efficient to trigger apoptosis. ${ }^{42}$

In prostate cancer cells characterized by androgenindependent growth, simvastatin displays synergistic toxicity with another mevalonate pathway inhibitor, the bisphosphonate alendronate. Unlike statins that deplete isoprenoid biosynthetic route products by inhibiting HMG-CoA reductase, alendronate and other bisphosphonates inhibit the mevalonate pathway at the level of farnesyl diphosphate synthase by virtue of molecular mimicry. Hence, at low doses, simvastatin along with alendronate decreases the viability of these cells. This event is accompanied by the stimulation of the c-JUN and the induction of apoptosis. However, this is not the case in androgen-dependent prostate cancer cells, where no such anticancer synergy is observed. ${ }^{44}$ When prostate cancer cells are incubated with conditioned medium obtained from mouse calvaria, insulin-like growth factor-1 receptor (IGF1R) is upregulated. Simvastatin abolishes this induction of IGF1R. Given that this receptor mediates the prosurvival effects of IGF-1 which is released by the bone matrix, this molecular event is of pivotal importance. Moreover, simvastatin acts in a synergistic manner with the IGF1R antagonist NVP-AEW541 to trigger apoptosis in prostate cancer cells. These findings indicate the value of simvastatin in the modulation of the dynamic interactions between prostate cancer cells and bone microenvironment in prostate cancer skeletal metastases. ${ }^{45}$ Another antimetastatic property of simvastatin is its ability to disrupt the interaction among the adhesion molecules expressed on prostate cancer cells (av $\beta 3$ integrin) and vascular endothelial cells (ICAM-1) as well as to preserve the endothelial barrier integrity. ${ }^{46}$

Simvastatin exhibits cytostatic effects (G0/G1 arrest) in a peroxisome proliferator-activated receptor- $\gamma$ (PPAR- $\gamma$ )dependent manner, as well as antimigratory and anti-invasive properties in bladder cancer cells. Further, in these cells, simvastatin controls the expression of epithelial-to-mesenchymal transition (EMT)-associated molecules, exemplified by E-cadherin, which is elevated, and $\beta$-catenin, which is decreased upon exposure to simvastatin. ${ }^{47}$

In leiomyoma cells, the ability of simvastatin to trigger apoptosis has been attributed to the targeting of calcium-permeable voltage-gated channels, ${ }^{48}$ while in renal cancer cells, the proapoptotic and antimetastatic functions of this drug have been linked to perturbed mammalian target of rapamycin (mTOR), JAK2/STAT3 and ERK signaling. Colon cancer cell viability is reduced by simvastatin through the downregulation of the prosurvival factors Bcl-xL and Bcl-2 and by the suppression of the expression of the apoptosis inhibitors, cIAP1 and cFLIP ${ }^{49}$ In a seemingly paradoxical manner, the sustained activation of ERK by simvastatin is required for drug-induced apoptosis in HT-29 human colon cancer cells, whereas, in contrast, IGF-1-triggered ERK/Akt activation is counteracted by simvastatin that stimulates apoptosis. ${ }^{50}$

Further, simvastatin increases the cytotoxic effects of irradiation combined with the anti-epidermal growth factor receptor (anti-EGFR) antibody cetuximab in head and neck squamous cell carcinoma (HNSCC) cells. Experimental 
data indicate that this antitumor activity is mechanistically associated with the suppression of ERK1/2-, STAT3- and AKT-dependent pathways and the induction of apoptotic cell death. ${ }^{51}$ In human lymphoma and melanoma cells, the antitumor function of simvastatin is attributed both to its ability to sensitize to bortezomib-mediated apoptosis or to induce apoptosis, respectively, as well as to its ability to impinge on the expression of CDK inhibitors (p21 Waf1/Cip1, p27 Kip1), thereby halting cell cycle progression. ${ }^{52,53}$ In melanoma cells, simvastatin as well as lovastatin and a statin that is not used at the clinical setting (mevastatin) are known to exhibit antiproliferative and anti-invasive properties. ${ }^{54}$ On the other hand, in multiple myeloma cells, simvastatin can induce both apoptosis and necrosis. ${ }^{55}$ Also, simvastatin enhances the chemosensitivity of multiple myeloma cells by disrupting an HMG-CoA/GGPP/Rho/ROCK pathway, which confers cell adhesion-mediated drug resistance (CAM-DR) to them. ${ }^{56}$

A mechanism by which simvastatin triggers apoptosis in SH-SY5Y neuroblastoma cells is through causing depletion of dolichol phosphate, which is produced throughout the mevalonate pathway. This isoprenoid compound serves as a sugar donor in the multistep process of protein N-glycosylation in the endoplasmic reticulum (ER). Impaired protein $\mathrm{N}$-glycosylation results in the activation of the unfolded protein response (UPR)-related molecules BiP and CHOP, as well as in cellular stress and apoptotic death. Of note, this proapoptotic effect of simvastatin is dolichol-reversible. In addition, in neuroblastoma and rhabdomyosarcoma cells, simvastatin-mediated dolichol depletion precludes the full glycosylation of ABCB1 transporter, a protein that has been linked to the phenomenon of multidrug resistance in cancer cells. Also, simvastatin causes a drop in the transportation rates of $\mathrm{ABCB} 1$ in neuroblastoma cells. ${ }^{57}$

Interference of simvastatin with the Rho GTPase/ Hippo-YAP/CD168 pathway is not only documented in vitro as mentioned above, ${ }^{39}$ but also in human breast cancer xenografts. The importance of this finding is underlined by the fact that CD168 along with YAP is found to be overexpressed in clinical specimens from patients with invasive breast cancer. ${ }^{39}$ Also, in MDA-MB-231 xenografts, simvastatin prevents the occurrence of bone metastasis, and this has been attributed to an inverse relationship between the expression of CD44 and p53, which is associated with drug administration. ${ }^{38}$ In immunodeficient mouse strains xenografted with tamoxifenresistant breast cancer cells, simvastatin acts as a negative modulator of the replication licensing factor (RLF), MCM7. Simvastatin restores the sensitivity of tamoxifen-resistant tumors to tamoxifen and suppresses tumor growth. ${ }^{42}$ In animal models of triple-negative breast cancer (TNBC), simvastatin has been found to engage a FOXO3a-mediated pathway to decrease the metastatic potency of malignant cells. ${ }^{58}$ Another notable in vivo antitumor activity of simvastatin is that it inhibits lung cancer metastasis to the bones in murine xenografts. ${ }^{31}$ Moreover, simvastatin exhibits synergistic anticancer effects in mouse HNSCC xenografts, in conjunction with radiotherapy and cetuximab. ${ }^{51}$

The antitumor properties of simvastatin are also evident in human renal carcinoma xenografts. ${ }^{59}$ Liposomal simvastatin administration yielded encouraging results in mice with melanoma. Mechanistically, the observed antitumor effect was demonstrated to be related to the ability of simvastatin to oppose the pro-oxidant function of tumor-associated macrophages (TAMs). ${ }^{60}$ This is also the case of pravastatin, which, upon administration in a liposomal formulation to melanoma-bearing mice, exhibits anti-inflammatory properties. Moreover, liposomal pravastatin was reported to upregulate major histocompatibility complex (MHC) class I expression in tumors, thereby possibly positively influencing tumor immunosurveillance. ${ }^{61}$

Simvastatin opposes the development of tumors in the mouse model of colitis-associated colon cancer and exhibits proapoptotic and antiangiogenic effects in colon cancer xenografts. ${ }^{49}$ In addition, simvastatin acts in synergy with bevacizumab to inhibit the growth of human colorectal cancer (CRC) xenografts and their ability to give rise to metastases. ${ }^{62}$ More recently, simvastatin has been reported to serve as an antiangiogenic factor in CRC in vivo by regulating a HER2/ VEGF signaling pathway. ${ }^{63}$

Moreover, simvastatin prevents virus-driven lymphomagenesis in immunodeficient mice ${ }^{64}$ and functions to impede mammary tumorigenesis in rodents induced by irradiation at the earliest stages. ${ }^{65}$ In the bone marrow of immunodeficient mice, simvastatin reduces the clonogenic capacity of human myeloblastic leukemia cells. ${ }^{66}$ In rhabdomyosarcoma xenografts, clinically relevant doses of simvastatin inhibit tumor growth, while in xenograft models of neuroblastoma and rhabdomyosarcoma, simvastatin displays synergistic proapoptotic effects with cyclophosphamide. ${ }^{57}$

Aside from simvastatin, rosuvastatin and pravastatin also exhibit antitumor function. Rosuvastatin, has been reported to suppress the activity of arginase (an urea cycle enzyme) and to reduce the levels of polyamines, both in the serum and tumor tissue in mouse models of breast cancer. ${ }^{67}$ These data add another level of complexity to statins' antitumor mechanism of action, given that arginase, its substrate arginine and polyamines participate in perplexed signaling pathways and 
are involved in tumor biology. ${ }^{68-71}$ On the other hand, pravastatin displays remarkable chemopreventive efficacy in rodent models of chemical-induced colon carcinogenesis. ${ }^{72,73}$

\section{Lovastatin}

Lovastatin stimulates caspase-dependent apoptotic death of melanoma cells in a GGPP-reversible manner. ${ }^{74}$ Aside from melanoma cells, lovastatin induces apoptosis in a wide range of human cancer cells, including medulloblastoma and malignant mesothelioma cells..$^{75-80}$

Lovastatin triggers apoptosis in different lung cancer cell lines by affecting Bax levels and stimulating p53. ${ }^{81}$ Further, lovastatin overrides resistance to gefitinib-induced apoptosis in NSCLC cells carrying mutant K-RAS by positively and negatively modulating the expression of Bax and Bcl-2, respectively, ${ }^{82}$ while it inhibits NSCLC cell adhesion and migration through depleting lipid rafts from cholesterol. ${ }^{83}$ Of note, the RLF MCM2 has been identified as a target of putative therapeutic activity of lovastatin in human NSCLC. Actually, exposure of NSCLC cells to lovastatin results in the decrease of MCM2 levels in a JNK-dependent fashion. ${ }^{84}$

In colon cancer cell lines, lovastatin potentiates the cytotoxic effects of commonly used chemotherapeutics such as cisplatin and 5-fluorouracil (5-FU) by upregulating the expression of Bax and suppressing Bcl-2. ${ }^{85}$ Celecoxibinduced apoptosis in colon cancer cells is increased by lovastatin, ${ }^{86}$ while in colon cancer cells, NSCLC cells as well as in SCC9 cells, this statin potentiates the cytotoxicity of gefitinib. ${ }^{87}$

Lovastatin along with simvastatin induces cell cycle arrest and stimulates apoptosis in prostate cancer cells by affecting the expression of a series of cell cycle regulators (D-type cyclins, $\mathrm{pRb}$ and the CDK inhibitors, $\mathrm{p} 21 \mathrm{Waf1} / \mathrm{Cip} 1$ and p27 Kip1) and through activating a RhoA/caspase-dependent pathway. ${ }^{88}$ In these cells, lovastatin has also been reported to decrease E2F1 levels to trigger apoptosis. ${ }^{89}$ Antitumor properties of lovastatin have also been reported in glioblastoma cells, where lovastatin exhibits antiproliferative and anti-invasive properties by inhibiting small GTPase (Rac1 and H-Ras) isoprenylation. ${ }^{90}$

Another mechanism by which lovastatin indirectly displays anticancer function is through prevention of the adenosine triphosphate (ATP)-dependent extrusion of the antileukemic drug imatinib from the cytosol of CD34 antigen-expressing chronic myeloid leukemia (CML) cells by multidrug resistant transporters, namely, $\mathrm{ABCG} 2$ and $\mathrm{ABCB} 1$. These effects of lovastatin are cholesterol-dependent. ${ }^{91}$ In human B lymphoma cells, the antiproliferative effects of lovastatin have been attributed to its antioxidant potency as well as to its ability to suppress the expression of the calcium-permeable channel transient receptor potential canonical 6 (TRPC6) ${ }^{92}$

An antibody microarray analysis showed that the expression of a set of 37 proteins is altered in response to lovastatin in MDA-MB-231 triple-negative aggressive breast cancer cells. Remarkably, the apoptosis-related proteins, death receptor 3 (DR3) and caspase-7, as well as the tumor-suppressor, p57Kip2, were found to be upregulated among other proteins, whereas the cell-cycle regulatory protein CDK4 and apoptosisinducing factor (AIF) were downregulated. Transglutaminase II (a mediator of N-cadherin switching) and hypoxia-inducible factor $1 \alpha(\mathrm{HIF}-1 \alpha)$ that are associated with the EMT phenomenon and matrix metalloproteinase (MMP)-7, which is known to be related with metastasis, were also reported to be negatively modulated by lovastatin in these cells. ${ }^{93}$ In leukemia cells of human origin, lovastatin displays synergistic effects with the clinically used antimetabolite, cytarabine. ${ }^{94}$

Intriguingly, lovastatin dampens the dimerization of the cancer-associated molecule EGFR and downstream Aktdependent signaling in a GGPP-reversible fashion. This leads to the suppression of global protein synthesis in squamous cell carcinoma cells. ${ }^{95}$ In addition, lovastatin may prevent tumorigenesis, which takes place on the ground of chronic inflammation, given that in vitro experimentation showed that this statin markedly prevents the oxidative damage of DNA evoked by stimulated phagocytes ${ }^{96}$ Also, Ames testing suggests that lovastatin as well as atorvastatin may exhibit chemopreventive activity, since both these drugs inhibit the action of mutagens. ${ }^{97}$

In vivo, lovastatin is known to enhance the antimelanoma effects of cisplatin at the preclinical level ${ }^{98}$ and increase the anticancer function of tumor necrosis factor- $\alpha^{99}$ and doxorubicin in different mouse tumor models. ${ }^{99}$ In a mouse model of ascites tumor, lovastatin triggers apoptosis in Dalton's lymphoma ascitic cells, ${ }^{100}$ while in rats, this drug halts metastatic dissemination of fibrosarcoma and lymphoma cells. ${ }^{101,102}$ Besides, lovastatin reduces the metastatic potential of mouse mammary tumors and melanomas. ${ }^{103,104}$ Further, in a manner that is unrelated to K-RAS mutational status or expression, lovastatin inhibits nitrosamine-induced tumorigenesis in murine lungs. ${ }^{105}$ Of note, in different murine tumor models, lovastatin is known to protect the myocardium from doxorubicin-induced cell damage. ${ }^{99}$ In tumors of HER2/neu transgenes, lovastatin decreases the population of macrophages exhibiting an M2-like phenotype; a cell population which is known to control various aspects of carcinogenesis. In contrast, the population of effector $\mathrm{T}$ 
lymphocytes increases upon lovastatin treatment. At the same time, tumors get more oxygen and they become more accessible to anticancer drugs by virtue of lovastatin's property to trigger vascular remodeling in tumors. ${ }^{27}$

\section{Atorvastatin}

In vitro experimentation using human pancreatic cancer cells demonstrated that atorvastatin displays antitumor synergy with the FTI tipifarnib and the cyclooxygenase-2 (COX-2) inhibitor celecoxib. ${ }^{106}$ In HNSCC cells, atorvastatin displays inhibitory activity on RhoC, a small GTPase and metastasis marker in HNSCC that has to be prenylated in order to be functional. Atorvastatin impairs the proliferation of HNSCC cells and reduces their motility and invasiveness. ${ }^{107}$ In A549 cells, a TGF- $\beta 1 /$ sphingosine kinase 1 (SphK1) axis has been recently characterized. Inhibition of this axis by atorvastatin is associated with the partial suppression of the EMT phenomenon and, hence, mitigation of the metastatic potency of these NSCLC cells. In addition, atorvastatin prevents the TGF- $\beta 1-$ mediated induction of the EMT-promoting transcription factor, ZEB1. This molecular event is also associated with the suppression of the migratory activity of A549 cells by atorvastatin. ${ }^{108}$

EH domain-binding protein 1 (EHBP1) has been found to serve as a mediator of atorvastatin's purinergic (P2X7), signaling-dependent, anti-invasive activity in prostate cancer cells, which are positive for the tumor suppressor protein PTEN. In these cells, EHBP1 physically associates with the invasiveness-related guanine nucleotide exchange factor (GEF), P-Rex1. In other cancer cell lines, statins also suppress invasive growth through interfering with a P2X7dependent pathway that modulates the nuclear phospho-Akt levels. The importance of these findings is substantiated by population genetic data suggesting that a loss of function allele coding for a $\mathrm{P} 2 \mathrm{X} 7$ receptor variant is correlated with nonaggressive cancer, in contrast to the common allele which is associated with aggressiveness. ${ }^{109}$ Mechanistically, the antimigratory/anti-invasive function of atorvastatin in breast cancer principally involves suppression of the expression of urokinase-type plasminogen activator (uPA), MMP-9 and the basic helix-loop-helix (bHLH) transcription factor, Twist. ${ }^{29}$ The different signaling routes used by atorvastatin to suppress the migratory and invasive potential of malignant cells in vitro are collectively depicted in Figure 1. Importantly, atorvastatin dampens the expression of the RLF MCM7 and induces genomic damage and apoptosis in tumor cells in a pRb-deficient background to a greater extent than in the presence of $\mathrm{pRb}$ in a similar way as simvastatin does, both in an in vitro and an in vivo setting. ${ }^{6}$
In $\operatorname{Pan}^{k r a s / p 53}$ mice which are engineered to carry Kras ${ }^{\mathrm{G} 12 \mathrm{D}}$ and $\mathrm{p} 53^{\mathrm{R} 172}$ mutations, thereby genetically and phenotypically resembling the human pancreatic carcinogenesis, nutritional supplementation with atorvastatin resulted in a decrease of the proliferation index of the tumors and their shrinkage. In fact, treatment with atorvastatin or the FTI tipifarnib (R115777) prevented protein prenylation and halted the growth of malignant cells. Importantly, atorvastatin decreased neutrophil infiltration in chronic pancreatitis near the tumor in transgenes. ${ }^{28}$ The latter finding is important given, the interrelation between inflammation and tumorigenesis. ${ }^{10,111}$

In addition, analysis in pancreatic tumor xenografts in mice demonstrated that atorvastatin displays antitumor synergy with the COX-2 inhibitor celecoxib and tipifarnib. ${ }^{106}$ In rats, combined administration of atorvastatin with either naproxen or sulindac, two marketed nonsteroidal antiinflammatory drugs (NSAIDs), could markedly inhibit inflammatory signaling and lower the incidence of colon adenocarcinomas. ${ }^{112}$ In line with the latter finding, atorvastatin acts in synergism with the COX-2 inhibitor celecoxib to suppress tumorigenesis in a prostate cancer xenograft mouse model ${ }^{113}$ or the progression of the androgen-dependent pattern of prostate tumor growth to androgen independence ${ }^{114}$ as well as the formation of intestinal polyps in the mouse familial adenomatous polyposis (FAP) model APCmin. ${ }^{115}$

Further, there are reports indicating the in vivo antitumor function of atorvastatin in head and neck cancer, MYCinduced lymphoma and breast cancer. In mice with head and neck cancer, atorvastatin suppresses tumor angiogenesis and the occurrence of distant metastases. ${ }^{107}$ The antitumor activity of atorvastatin in murine conditional transgenes for modeling MYC-driven lymphomagenesis is mechanistically associated with the suppression of the Ras/ERK/MYC axis upon the pharmacologic inhibition of HMG-CoA reductase. ${ }^{116}$ In an orthotopic model of breast cancer metastasis, a micelle-based nanosystem for the delivery of atorvastatin inhibited distant metastases of breast cancer cells. ${ }^{29}$

\section{Fluvastatin}

The fluorinated compound fluvastatin displays selective toxicity toward malignant rat glial cells, but it does not affect normal neurons. Its multilevel antitumor activity is molecularly associated with the stimulation of the JNK1/2 axis, the suppression of ERK1/2-dependent signaling, as well as the impaired secretion of VEGF and MMP-9. ${ }^{117}$ Paradoxically, statins are not only involved in the inhibition of GTPase isoprenylation, but also function as glycosylation inhibitors to suppress tumor growth. In fact, fluvastatin inhibits glycosylation of the class III receptor tyrosine kinase FMS-like tyrosine 


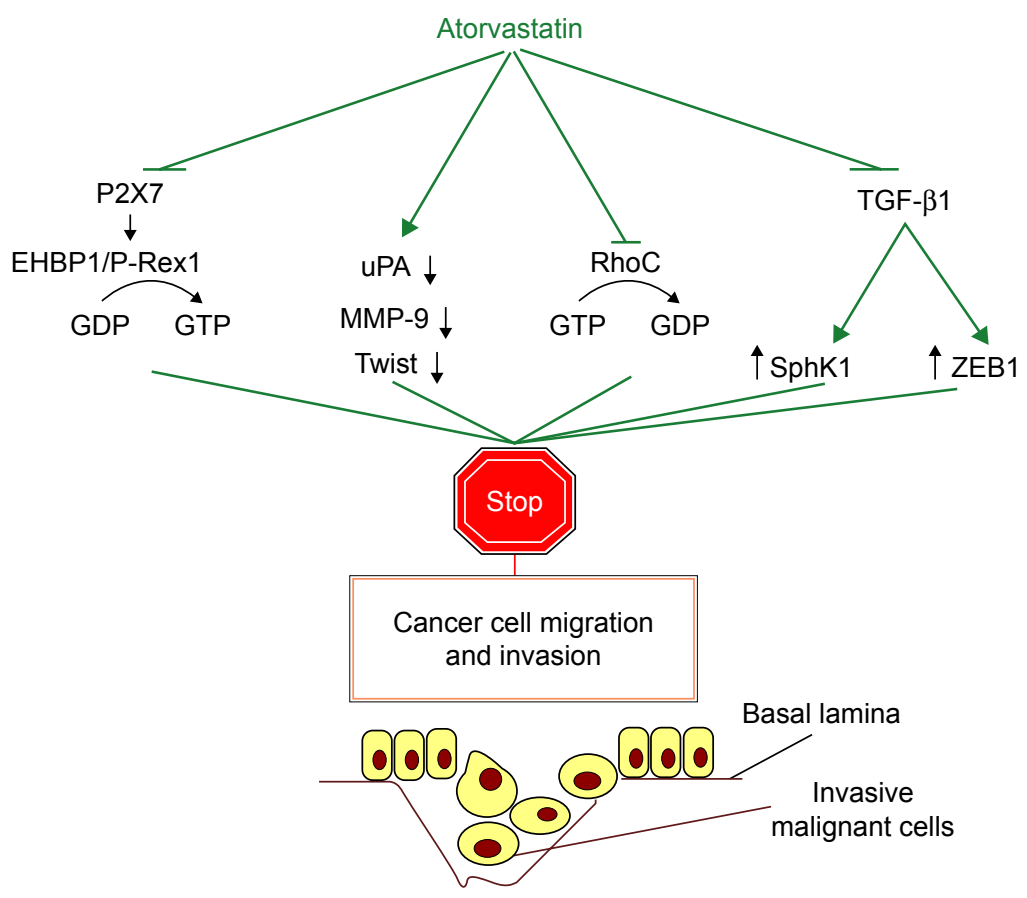

Figure I Signaling pathways mechanistically involved in atorvastatin's ability to inhibit the migratory and invasive potential of different types of cancer cells in vitro. Notes: One of the mechanisms that have been reported in PTEN-positive prostate cancer cells involves the blockage of a purinergic P2X7/EHBPI/P-RexI route. On the other hand, the antimigratory/anti-invasive properties of atorvastatin in breast cancer cells have been linked to the downregulation of the expression of a series of different proteins, that is, uPA, the bHLH transcription factor Twist as well as MMP-9. In HNSCC cells, the ability of atorvastatin to inhibit cancer cell migration/invasion relays on the drug-induced impaired function of the small GTPase, RhoC. In NSCLC cells, atorvastatin hinders the metastatic potency through inhibiting TGF- $\beta$ I-dependent pathways which are associated with the upregulation of SphKI and the EMT-promoting transcription factor, ZEBI. Downward pointing arrows refer to negative regulation of the expression by atorvastatin. P-RexI exhibits GEF activity (ie, enables the release of GDP and the subsequent binding of a GTP molecule by a GTPase), whereas RhoC exhibits GTPase activity (ie, it catalyzes the hydrolysis of GTP to GDP).

Abbreviations: ATP, adenosine triphosphate; bHLH, basic helix-loop-helix; EMT, epithelial-to-mesenchymal transition; GDP, guanosine diphosphate; GEF, guaninenucleotide exchange factor; GTP, guanosine triphosphate; HNSCC, head and neck squamous cell carcinoma; MMP, matrix metalloproteinase; NSCLC, non-small cell lung cancer; PTEN, phosphate and tensin homolog deleted on chromosome I0; SphKI, sphingosine kinase I; uPA, urokinase-type plasminogen activator.

kinase-3 (FLT3), which commonly harbors activating mutations in acute myeloid leukemia (AML) and cannot be successfully targeted. This molecular event is associated with hampered MAPK and AKT activation and killing of cells expressing mutant FLT3 (FLT3/ITD). ${ }^{26}$ This is a good example of how a class of pharmacologic agents somehow interferes with more than one type of protein's posttranslational modification to achieve their pleiotropic biologic effects. Regarding the antitumor activity of statins in hematologic malignancies, evidence has been provided for the combined antileukemic effects of fluvastatin with all-trans retinoic acid (ATRA). ${ }^{118}$

In renal cancer cells, fluvastatin's antitumor activity has been suggested to be mediated by the derepression of the function of a negative modulator of translation initiation, namely, programmed cell death 4 (PDCD4), through the inhibition of the mTOR. ${ }^{119}$ Interestingly, fluvastatin as well as lovastatin reduce EGF-stimulated human pancreatic cancer cell invasion by the inhibition of RhoA isoprenylation. ${ }^{120}$ Of note, the stimulation of the production of the antitumor cytokine interleukin-18 by human monocytes is thought to account for an antitumor mechanism of action of all the aforementioned statins (fluvastatin, simvastatin and pravastatin). ${ }^{121}$

Fluvastatin is known to confer a survival benefit to leukemic mice with FLT3/ITD. ${ }^{26}$ In addition, fluvastatin negatively influences the ability of mouse renal cancer cells to give rise to metastases in the lungs of mice. ${ }^{122}$

\section{Preclinical data}

\section{Ezetimibe}

A study carried out by Solomon et al indicates that not only statins, but also ezetimibe exhibit antitumor activity. Actually, ezetimibe was reported to act independently, but additively with the application of a low fat/no cholesterol (LFNC) diet in retarding tumor growth in severe combined immunodeficiency (SCID) mice implanted with human prostate tumors. Moreover, it was demonstrated that ezetimibe and LFNC exhibit additive, independent inhibitory effects on LNCaP cell proliferation and viability, as well as on tumor microvascularization through upregulating the expression of thrombospondin 1 (TSP-1), a well-established antiangiogenic 
factor. ${ }^{22}$ More experimentation is required to shed light on whether ezetimibe can halt the growth of other cancer cell types as well.

\section{Clinical data}

Data from Phase I and II clinical trials support that monthly administration of lovastatin at relatively high doses $(25 \mathrm{mg} /$ $\mathrm{kg}$ /day) for a week followed by a 3-week pause in patients with prostate cancer or central nervous system (CNS) tumors causes, in most cases, ubiquinone-reversible myopathy, but yields only minor and partial responses. ${ }^{123,124}$ Almost no objective responses were reported in patients with advanced gastric adenocarcinoma who received 7-day courses of lovastatin at a dose of $35 \mathrm{mg} / \mathrm{kg} /$ day every 28 days. ${ }^{125}$ However, a clinically relevant dose of pravastatin (40 $\mathrm{mg}$ /day) was found to extend life expectancy by two times in patients with advanced hepatocellular carcinoma (HCC) who had previously undergone transcatheter arterial embolization (TAE) followed by 5-FU administration, without causing myalgia, indicating its usefulness in adjuvant treatment. ${ }^{126}$ In line with this, chemoembolization is more efficacious in improving survival in HCC patients when it is combined with pravastatin at a dose of $20-40 \mathrm{mg} /$ day. ${ }^{127}$

A Phase II clinical study yielded promising results with clinically relevant doses of simvastatin (40 mg/day) combined with the conventional chemotherapeutic scheme FOLFIRI (folinic acid, 5-FU and irinotecan) in patients with metastatic CRC. ${ }^{128}$ Of note, certain monoclonal antibodies targeting the EGFR, exemplified by cetuximab, have been shown to be of clinical benefit, provided that KRAS does not harbor mutations. Hence, it has been hypothesized that simvastatin, which interferes with RAS posttranslational modification (prenylation), might restore the sensitivity to cetuximab. Unfortunately, this hypothesis is not valid, as reported by a Phase II clinical study in previously treated, metastatic CRC patients. Specifically, only 4 out of 18 patients who were enrolled into the study experienced disease stabilization at 12.5 weeks after cetuximab was first administered. This does not suggest any clinical applicability of simvastatin as a KRAS modulator and, hence, an agent that would restore sensitivity to cetuximab in metastatic CRC patients carrying KRAS mutations. ${ }^{129}$ This also holds true for another anti-EGFR monoclonal antibody, namely, panitumumab, as indicated by another Phase II clinical study. ${ }^{130}$ An analysis retrospectively assessing the data stemming from the CAIRO2 Phase III clinical trial reported that the usage of statins does not beneficially influence either progression-free survival (PFS) or overall survival of metastatic CRC patients with the KRAS mutant gene who received chemotherapeutic agents in conjunction with the monoclonal antibodies, cetuximab and bevacizumab. ${ }^{131}$ On the other hand, in Danish individuals suffering from different types of cancer, the use of statin reduces the rates of malignancy-associated death, as shown by a retrospective analysis. ${ }^{132}$ Considering the latter analysis, however, some phenomena including the preferential prescription of statins to nonsmokers by some general practitioners or other comorbidities in statin users (eg, CVD) may have led to data misinterpretation and/or incorrect inferences. ${ }^{133,134}$

Hopefully, certain statins, in a manner that depends upon their physicochemical properties (ie, their hydrophobicity), increase the PFS rates of patients suffering from the most life-threatening type of primary breast cancer; inflammatory breast cancer, as demonstrated in an observational study. ${ }^{135}$ This is in line with the results from a Phase II study where it was found that the preoperative administration of high doses of atorvastatin manages to decrease the proliferation of tumor cells that express HMG-CoA reductase in women with primary invasive breast cancer. ${ }^{136}$ In window trials enrolling breast cancer patients, comparison of the transcriptome before and after treatment with high dose $(80 \mathrm{mg} /$ day $)$ of atorvastatin for 14 days prior to surgery has shown that the mRNA levels of molecules associated with immune response, apoptosis (GADD45B) and MAPK signaling (eg, the DUSP1 phosphatase) are statistically significantly affected, ${ }^{137}$ while this atorvastatin dosage regimen also modulates cyclin D1 and the oncosuppressor $\mathrm{p} 27 \mathrm{Kip} 1$ proteins in breast cancer, negatively and positively, respectively. ${ }^{138}$ Remarkably, a pilot perioperative study demonstrated that fluvastatin at clinically attainable dosages (20 or $80 \mathrm{mg} /$ day) exhibits potent chemopreventive properties in high-grade early-stage breast cancer patients. ${ }^{139}$

In a cohort of white postmenopausal women, the selfreported consumption of simvastatin, lovastatin as well as other lipophilic statins over a follow-up period of 10.5 years was associated with an elevated risk for non-melanoma skin cancer (NMSC), irrespective of other factors including sunlight exposure, vitamin D intake, smoking and body mass index (BMI). Therefore, researchers did not exclude the scenario of a protumorigenic - possibly immunomodulatory - activity of statins and recommended that subjects with a family history of NMSC or those who are carcinogenesis prone due to their skin type should avoid the consumption of the aforementioned statins. ${ }^{140}$

Intriguingly, the results of other previous studies regarding the putative link between NMSC and statin usage are 
discrepant, both incriminating this category of antihypercholesterolemic agents for $\mathrm{NMSC}^{141-144}$ and pinpointing to a protective role of statins against the development of cancer ${ }^{145-147}$ or even not suggesting any statistically significant relationship between them. ${ }^{148-151}$ In accordance with the latter scenario, patients suffering from metastatic CRC who received chemotherapy and then were enrolled into a Phase III study in South Korea did not experience any clinical benefit (PFS) when $40 \mathrm{mg}$ of simvastatin were added to a XELIRI/FOLFIRI chemotherapy regimen. ${ }^{152}$ Based on the statistics on statin prescription (simvastatin ranked first in statin prescription in the $\mathrm{UK}^{153}$ ) and the fact that atorvastatin is one of the most extensively studded statins as an antitumor agent at the clinical basis, Table 1 summarizes selected completed or active clinical trials evaluating the usage of these two antihypercholesterolemic agents in different types of malignancy or precancerous conditions.

More clinical trials are necessary to evaluate the antitumor function of statins. The results from the clinical trials that have already been completed or are still ongoing (NCT02026583, NCT01992042) are, therefore, much awaited. Regarding ezetimibe, yet, no clinical evidence has been provided supporting its antitumor function. The relationship between ezetimibe and tumorigenesis is actually obscure. ${ }^{154} \mathrm{~A}$ multinational study, namely, SEAS, investigating the occurrence of cancer in patients with aortic stenosis who received

Table I Selected active or completed clinical trials on simvastatin and atorvastatin for cancer therapeutics and/or cancer prevention

\begin{tabular}{|c|c|c|c|c|}
\hline Setting & Pharmacologic intervention(s) & Phase & Status & $\begin{array}{l}\text { Clinical trials } \\
\text { Gov identifier }\end{array}$ \\
\hline Gastric cancer & Simvastatin; placebo & Phase III & Completed & NCT0I099085 \\
\hline Breast cancer & Simvastatin & Phase II & Completed & NCT00334542 \\
\hline Pancreatic cancer & Gemcitabine + simvastatin; Gemcitabine + placebo & Phase II & Completed & NCT00944463 \\
\hline Bladder cancer & Metformin; simvastatin & Phase II & Recruiting & NCT02360618 \\
\hline Metastatic colorectal cancer & Cetuximab/irinotecan/simvastatin & Phase II & Completed & NCT0I28I76I \\
\hline Colorectal cancer & Simvastatin & Phase II & Recruiting & NCT02026583 \\
\hline Lung cancer & Simvastatin; gefitinib only & Phase II & Completed & NCT00452244 \\
\hline Small cell lung cancer & Irinotecan; cisplatin; simvastatin & Phase II & Completed & NCT00452634 \\
\hline Breast cancer & Metformin/simvastatin/fulvestrant & Phase II & Recruiting & NCT03192293 \\
\hline Breast cancer & $\begin{array}{l}\text { Anastrozole; simvastatin; other: pharmacologic } \\
\text { study; procedure: adjuvant therapy }\end{array}$ & Phase II & Completed & NCT00354640 \\
\hline Breast cancer & Nimesulide; simvastatin; placebo & Phase II & Completed & NCTOI 500577 \\
\hline Metastatic colorectal cancer & Simvastatin & Phase II & Completed & NCT003I3859 \\
\hline Adenocarcinoma of rectum & Simvastatin & Phase II & Recruiting & NCT02I6I822 \\
\hline $\begin{array}{l}\text { Relapsed and/or refractory } \\
\text { pediatric solid and CNS tumors }\end{array}$ & $\begin{array}{l}\text { Simvastatin; cyclophosphamide; topotecan; } \\
\text { myeloid growth factor }\end{array}$ & Phase I & Recruiting & NCT02390843 \\
\hline Prostate cancer & Ezetimibe $10 \mathrm{mg}-$ simvastatin $40 \mathrm{mg}$ & Early Phase I & Recruiting & NCT02534376 \\
\hline $\begin{array}{l}\text { Cirrhosis (liver cancer } \\
\text { prevention) }\end{array}$ & Simvastatin; placebo & Phase II & Recruiting & NCT029688I0 \\
\hline Brain metastases & Simvastatin (in addition to radiation therapy) & Phase II & Completed & NCT02104I93 \\
\hline Multiple myeloma & Simvastatin & Phase II & Completed & NCT00399867 \\
\hline Chronic lymphocytic leukemia & Simvastatin & Phase I & Completed & NCT00828282 \\
\hline Breast cancer & Atorvastatin; metformin & Early Phase I & Recruiting & NCTOI 980823 \\
\hline Breast cancer & Letrozole and atorvastatin; fulvestrant; letrozole & Phase II & Recruiting & NCT02958852 \\
\hline Prostate cancer & Atorvastatin calcium; celecoxib & Phase II & Completed & NCT0I 220973 \\
\hline Prostatic neoplasms & Atorvastatin; placebo & Phase II & $\begin{array}{l}\text { Active, not } \\
\text { recruiting }\end{array}$ & NCT0I82I404 \\
\hline Endometrial cancer & Atorvastatin & Early Phase I & Recruiting & NCT02767362 \\
\hline Breast cancer; postmenopausal & Atorvastatin & Phase II & Completed & NCT008I 6244 \\
\hline $\begin{array}{l}\text { Colorectal cancer; } \\
\text { precancerous condition }\end{array}$ & $\begin{array}{l}\text { Atorvastatin calcium; oligofructose-enriched } \\
\text { inulin; sulindac; placebo }\end{array}$ & Phase II & Completed & NCT00335504 \\
\hline $\begin{array}{l}\text { Breast cancer; precancerous } \\
\text { condition }\end{array}$ & Atorvastatin calcium & Phase I & Completed & NCT0063748I \\
\hline Prostate cancer & $\begin{array}{l}\text { Atorvastatin; metformin; placebo (corresponding } \\
\text { to metformin) }\end{array}$ & Phase II & Recruiting & NCT02497638 \\
\hline Glioblastoma multiforme & Atorvastatin; temozolomide & Phase II & Recruiting & NCT02029573 \\
\hline Hepatocellular carcinoma & Atorvastatin; placebo oral tablet & Phase IV & Recruiting & NCT03024684 \\
\hline
\end{tabular}

Abbreviation: CNS, central nervous system. 
placebo compared to those who received simvastatin (40 mg daily) and ezetimibe (10 $\mathrm{mg}$ daily) reported that the latter are at higher risk for carcinogenesis. ${ }^{155}$ However, no such association was reported in a subsequent study enrolling a SEAS trial cohort from the UK, Denmark and Scandinavia. ${ }^{156}$ Clinical trials evaluating the possible anticancer therapeutic potency of ezetimibe in oncologic patients are necessary to enable its future repositioning in the field of oncology.

\section{Considerations for using and repurposing antihypercholesterolemic drugs}

In many studies, the anticancer function of statins on various cancer cell lines has been demonstrated, using them at clinically irrelevant doses. ${ }^{157-159}$ In other cases, however, statins display their anticancer properties at dosages that are clinically attainable. For instance, the $\mathrm{IC}_{50}$ (ie, $50 \%$ of growth suppression) of lovastatin in various cancer human cells is within the concentration range $0.3-2 \mu \mathrm{M} .{ }^{160}$ According to data stemming from experiments in animals, $2-4 \mu \mathrm{M}$ of lovastatin in serum is safe and toxicity becomes evident only at a concentration of $20-25 \mu \mathrm{M} .{ }^{161}$ Clinical data indicate that in cancer patients, even high plasma concentrations of lovastatin (up to $12 \mathrm{mM}$ ) administered for a short period ( $\leq 4$ days) are well tolerated. ${ }^{159}$

Statins display additivity and synergism with conventional chemo drugs and monoclonal antibodies (eg, antimetabolites, cisplatin, doxorubicin and cetuximab). ${ }^{85,94,98,162-164}$ In addition, there is accumulating evidence that statins act at low doses in synergism with NSAIDs as chemopreventive agents. ${ }^{165}$ Moreover, owing to the phenomenon of biotransformation by cytochrome P450 (CYP) 3A4 (expressed in gut and liver), the concentrations of statins required to achieve their antitumor effects may be actually much lower than the concentrations used for in vitro experiments. ${ }^{158}$ Hence, all these data open the possibility for the future use of statins as adjuvant agents for the treatment of cancer at dose schemes close to the current therapeutic anticholesterolemic dose.

Some people receiving statins experience myotoxicity and/or hepatotoxicity. In addition, coadministration of statins with certain drugs (including clarithromycin, erythromycin, azole antifungals and cyclosporine A) which inhibit CYP3A4the major statin-metabolizing CYP isoform - is prohibitive, since these agents increase the serum statin concentration, thereby exacerbating myopathy. ${ }^{166,167}$ Therefore, frequent monitoring of serum transaminases is highly recommendable, while statin-induced reduction of serum Q10 (a mevalonate pathway product) levels that has been associated with myopathy could be restored by ubiquinone supplementation. ${ }^{168}$
Great caution should also be exercised with regard to those patients who receive medication that is incompatible with statins exemplified by cyclosporine and macrolide antibiotics that inhibit CYP3A4. ${ }^{169,170}$ Regarding statin myotoxicity, particular caution should be paid in case that these drugs will eventually be repositioned in the field of oncology since malignancy and myopathy have been interrelated, while myopathy may also be ascribed to steroid consumption by cancer patients. ${ }^{171,172}$ Conceivably, in cases of myopathic patients, the use of statins as antitumor drugs would not be recommended. A major concern is that subjects suffering from type II diabetes mellitus who consume atorvastatin are likely to develop atorvastatin-induced autoimmune myositis (AtorAIM). Hallmarks of AtorAIM are: 1) detection of anti-HMG-CoA reductase autoantibodies in the serum of patients, 2) abnormal creatine kinase (CK) levels even when the administration of atorvastatin is being discontinued and 3) responsiveness to the intravenous immunoglobin (IVIG) induction therapy, although AtorAIM patients do not respond to corticosteroids. ${ }^{173}$

Since ezetimibe is devoid of the severe adverse effects of statins (eg, hepatotoxicity, myotoxicity) and has been proved to be safe and well tolerated, either in monotherapy or in combinational hypolipidemic therapy, ${ }^{174-176}$ it would be of great interest if future clinical trials would evaluate it as an antitumor agent. However, it should be noted that, ezetimibe in combination with cholesterol diet stimulates NFkB and local intestinal inflammation in guinea pigs. ${ }^{177}$ Given the interrelation between inflammation and intestinal cancer, ${ }^{178}$ more studies are needed to address whether ezetimibe could fuel intestinal carcinogenesis in humans under certain circumstances.

\section{Conclusion and future perspectives}

The putative usage of the pharmacologic agents discussed here, especially statins, in the field of oncology is not based on the same rationale as those for the mechanism of action of either chemotherapeutics ${ }^{179-181}$ or targeted anticancer drugs. ${ }^{182}$ Statins were first isolated and characterized as HMG-CoA reductase inhibitors in 1970 s, while lovastatin was the first statin that gained Food and Drug Administration approval as an antihypercholesterolemic drug in 1987. Hence, researchers started to make efforts to target cholesterol synthesis as a blood cholesterol-lowering strategy, even though two decades ago, published data ${ }^{183}$ indicated an interrelation between the biosynthetic pathway of cholesterol and cellular transformation. In early 1990s, it was hypothesized that the blockage of mevalonate pathway could suppress cancer cell growth. ${ }^{184}$ 
However, accruing experimental data presented above suggest that statins may be exploited as antitumor agents owing not solely to their isoprenoid biosynthesis-blocking property. Actually, statins are somehow molecularly "endowed" with pleiotropism, and therefore, they exhibit multilevel antitumor function(s) associated with the modulation of divergent signaling pathways, including cell life and death decisions, ${ }^{31}$ cell-to-cell adhesion, ${ }^{46}$ EMT, ${ }^{32}$ protein N-glycosylation, the UPR, ${ }^{57}$ DNA replication licensing, ${ }^{42} \mathrm{TAMs}^{60}$ or even angiogenesis. ${ }^{63}$ Thus, it becomes increasingly clear that statins act as versatile anticancer bulletins targeting pathways far beyond those that are known to link cholesterol and lipoprotein metabolism to carcinogenesis. ${ }^{185}$ Versatility at the signaling and physiologic level also holds true for the blood cholesterol-lowering drug ezetimibe, which displays an antiangiogenic mode of antitumor action. ${ }^{22}$

Additional clinical data are needed for statins to assess their antitumor potency. The results of ongoing clinical studies (eg, NCT01992042 and NCT02026583) are much awaited. It would also be very interesting to evaluate the antitumor properties of ezetimibe in oncologic patients, given that no such evidence has been provided for this antihypercholesterolemic agent so far, even though it is devoid of the major adverse effects associated with the use of statins.

A darling enterprise of the future is to delineate the mechanism(s) of the anticancer activity of non-antineoplastic marketed agents, which, in a similar manner to statins, are currently used for managing CVD - either prophylactically or therapeutically - given that CVD and cancer rank as the two leading causes of mortality globally. ${ }^{186}$ Aspirin, similar to statins, is a widely prescribed NSAID with well-established antitumor properties., ${ }^{9,187}$ Caffeine is commonly combined with aspirin in commercially available formulations and is also well known to exhibit antitumor function. ${ }^{188-190}$ Serum proteomics data (Figure S1) indicate that at the clinical level, administration of aspirin combined with caffeine compared to aspirin alone may affect (either positively or negatively) the levels of proteins in human serum that have been linked to cancer biology, cancer prognosis/diagnosis and prediction of the efficacy of anticancer medication. These proteins are TTR, ${ }^{191} \mathrm{RBP} 4,{ }^{192} \mathrm{Hp}^{193}$ and ApoA1. ${ }^{194}$ These hints would be very interesting to be experimentally validated in the future. Paradoxically enough, although several experimental data have been provided so far regarding the multilevel pharmacologic activity of aspirin or caffeine alone, ${ }^{9,195-198}$ only less amount of data has been published regarding the effects of aspirin combined with caffeine. ${ }^{199,200}$ Most importantly, research so far has focused on the analgesic properties of this combinational scheme. To the best of our knowledge, there is no evidence addressing whether such a pharmacologic combination is associated with superior antitumor function in comparison to that of either agent alone. If the scenario for anticancer synergism holds true, it would be interesting to delineate the signaling pathway(s) that is/are involved in the synergistic effect. Intriguingly, caffeine is an inhibitor of the activity of the master DNA damage response (DDR) kinases ATM and ATR, ${ }^{201}$ while an interplay between COX and ATR has been described. Actually, COX positively regulates ATR levels through a $\mathrm{COX} / \mathrm{PGE}_{2} / \mathrm{ERK} / \mathrm{ATR}$ axis in cancer cells and this pathway has been functionally associated with the acquisition of resistance to genotoxic agents. ${ }^{202}$ Thus, a major future challenge would be to assess whether aspirin combined with caffeine displays antitumor synergism and which molecular circuits are affected in the presence of both these agents with regard to tumorigenesis. Besides, another scenario which is worthy of investigation is a putative synergism between an NSAID such as aspirin and atorvastatin or another statin against tumorigenesis, or even the possible antitumorigenic synergism of a triple combination of an NSAID, a statin and caffeine, given that atorvastatin and celecoxib are known to display anticancer synergism. ${ }^{113}$ A synergism of such a double or triple combination in the prevention of androgen-independent pattern of growth of prostate cancer is also possible and merits investigation, as indicated by the former findings. ${ }^{114}$

Finally, another future challenge is to identify new cancer-associated molecular targets of statins by exploiting the predictive power of bioinformatics tools in order to develop novel antitumor therapeutic schemes. Consistent with this, an in silico analysis indicates that simvastatin not only serves as a negative modulator of MCM7 expression as it was previously mentioned, ${ }^{6,42}$ but also may physically interact with another RLF, the human protein CDT1. Specifically, bioinformatics indicate that simvastatin possibly binds at one up to three different binding sites on human CDT1 and predict that this putative binding of the drug interferes with the intermolecular interaction between CDT1 and its physical inhibitor, geminin (Figure 2). The importance of this prediction is substantiated by previous findings showing that silencing the expression of geminin is an emerging cancer cell-eliminating strategy irrespective of the p53 status which leaves normal or immortalized cells unaffected. This methodology is based on the geminin silencing-induced DNA re-replication and the consequent induction of genomic damage and programmed cell death. However, as it is reported, not all malignant human cells 


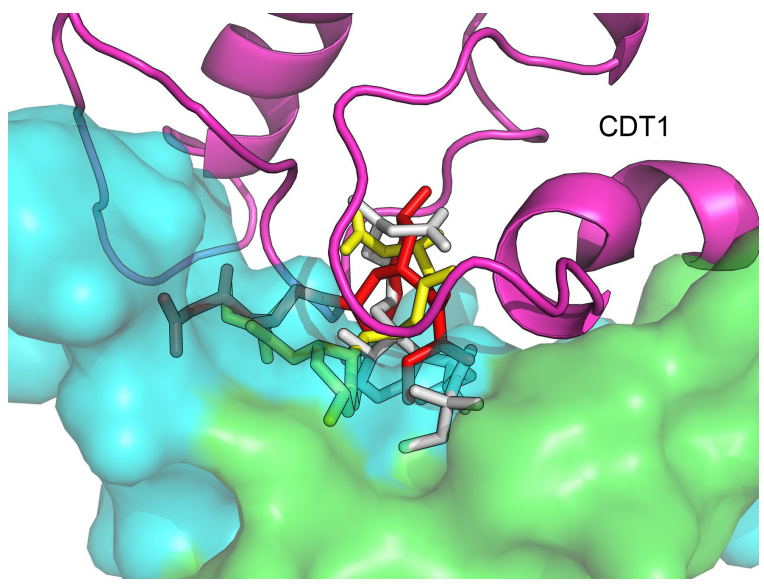

Figure 2 Docking of simvastatin on the human DNA replication licensing factor CDTI.

Notes: Autodock vina has been used to predict binding sites of simvastatin as a ligand (structure taken from Protein Data Bank, PDB:2WVR) on CDTI (chain C, PDB:4XW2) allowing flexible docking for the ligand. Three of the nine predicted binding sites of similar affinity $(\sim-5.5 \mathrm{kcal} / \mathrm{mol})$ are positioned in the interaction interface between CDTI and geminin (chains $A$ and $B, P D B: 4 X W 2$ ), indicating that simvastatin interferes with the CDTI:geminin complex and possibly destabilizes it. The figure has been produced using PyMol using the following coloring code: magenta for CDTI in cartoon representation, green and cyan for the geminin dimer in surface representation, red, yellow and gray for the three poses of simvastatin in sticks representation.

are equally affected by geminin silencing. In fact, HeLa and skin melanoma cells are not sensitive to geminin silencing. ${ }^{203}$ Conceivably, an attractive goal is to carry out in vitro assays to address whether simvastatin and/or another statin physically interferes with the binding of geminin at CDT1 as in silico analysis predicts. If this assumption holds true, it would be very interesting to assess the physiologic relevance of this interference. In case simvastatin or another statin hinders the CDT1:geminin interaction, it is plausible that the inhibition of geminin activity and statin treatment could exhibit synergistic cancer cell-killing effects in cancer cells that are sensitive to geminin silencing. In addition, geminin silencing-resistant cells could be sensitized in the presence of simvastatin. This testable prediction merits experimental validation that could open new avenues in cancer therapeutics.

\section{Disclosure}

The authors report no conflicts of interest in this work.

\section{References}

1. Simpson CB, James JC. The efficacy of mitomycin-C in the treatment of laryngotracheal stenosis. Laryngoscope. 2006;116(10):1923-1925.

2. Mearza AA, Aslanides IM. Uses and complications of mitomycin C in ophthalmology. Expert Opin Drug Saf. 2007;6(1):27-32.

3. Lu Y, Liu XF, Liu TR, et al. Celecoxib exerts antitumor effects in HL-60 acute leukemia cells and inhibits autophagy by affecting lysosome function. Biomed Pharmacother. 2016;84:1551-1557.
4. Vila-Leahey A, Oldford SA, Marignani PA, Wang J, Haidl ID, Marshall JS. Ranitidine modifies myeloid cell populations and inhibits breast tumor development and spread in mice. Oncoimmunology. 2016;5(7):e1151591.

5. Charles E, Hammadi M, Kischel P, et al. The antidepressant fluoxetine induces necrosis by energy depletion and mitochondrial calcium overload. Oncotarget. 2017;8(2):3181-3196.

6. Li J, Liu J, Liang Z, et al. Simvastatin and Atorvastatin inhibit DNA replication licensing factor MCM7 and effectively suppress RB-deficient tumors growth. Cell Death Dis. 2017;8(3):e2673.

7. Papanagnou P, Stivarou T, Tsironi M. Unexploited antineoplastic effects of commercially available anti-diabetic drugs. Pharmaceuticals (Basel). 2016;9(2)

8. Erices R, Cubillos S, Aravena R, et al. Diabetic concentrations of metformin inhibit platelet-mediated ovarian cancer cell progression. Oncotarget. 2017;8(13):20865-20880.

9. Papanagnou P, Baltopoulos P, Tsironi M. Marketed nonsteroidal antiinflammatory agents, antihypertensives, and human immunodeficiency virus protease inhibitors: as-yet-unused weapons of the oncologists' arsenal. Ther Clin Risk Manag. 2015;11:807-819.

10. Jensen K, Bikas A, Patel A, et al. Nelfinavir inhibits proliferation and induces DNA damage in thyroid cancer cells. Endocr Relat Cancer. 2017; 24(3):147-156

11. Russo A, Pellosi DS, Pagliara V, et al. Biotin-targeted Pluronic(®) P123/ F127 mixed micelles delivering niclosamide: A repositioning strategy to treat drug-resistant lung cancer cells. Int J Pharm. 2016;511(1): 127-139.

12. Ahn SY, Yang JH, Kim NH, et al. Anti-helminthic niclosamide inhibits Ras-driven oncogenic transformation via activation of GSK-3. Oncotarget. 2017;8(19):31856-31863.

13. Mei Z, Liang M, Li L, Zhang Y, Wang Q, Yang W. Effects of statins on cancer mortality and progression: A systematic review and meta-analysis of 95 cohorts including 1,111,407 individuals. Int J Cancer. 2017;140(5): 1068-1081.

14. Cai $X, H u X$, Tan $X$, et al. Metformin induced AMPK activation, G0/G1 Phase cell cycle arrest and the inhibition of growth of esophageal squamous cell carcinomas in vitro and in vivo. PLoS One. 2015;10(7):e0133349.

15. Weber C, Noels H. Atherosclerosis: current pathogenesis and therapeutic options. Nat Med. 2011;17(11):1410-1422.

16. Pelton K, Coticchia CM, Curatolo AS, et al. Hypercholesterolemia induces angiogenesis and accelerates growth of breast tumors in vivo. Am J Pathol. 2014;184(7):2099-2110.

17. Farnier M, Chen E, Johnson-Levonas AO, McCrary Sisk C, Mitchel YB. Effects of extended-release niacin/laropiprant, simvastatin, and the combination on correlations between apolipoprotein B, LDL cholesterol, and non-HDL cholesterol in patients with dyslipidemia. Vasc Health Risk Manag. 2014;10:279-290.

18. Itzhaki O, Greenberg E, Shalmon B, et al. Nicotinamide inhibits vasculogenic mimicry, an alternative vascularization pathway observed in highly aggressive melanoma. PLoS One. 2013;8(2):e57160.

19. Elangovan S, Pathania R, Ramachandran S, et al. The niacin/butyrate receptor GPR109A suppresses mammary tumorigenesis by inhibiting cell survival. Cancer Res. 2014;74(4):1166-1178.

20. Gao J, Liao J, Yang GY. CAAX-box protein, prenylation process and carcinogenesis. Am J Transl Res. 2009;1(3):312-325.

21. Schooling CM, Au Yeung SL, Freeman G, Cowling BJ. The effect of statins on testosterone in men and women, a systematic review and metaanalysis of randomized controlled trials. BMC Med. 2013;11:57.

22. Solomon KR, Pelton $\mathrm{K}$, Boucher K, et al. Ezetimibe is an inhibitor of tumor angiogenesis. Am J Pathol. 2009;174(3):1017-1026.

23. Yu CC, Lai WT, Shih KC, et al. Efficacy, safety and tolerability of ongoing statin plus ezetimibe versus doubling the ongoing statin dose in hypercholesterolemic Taiwanese patients: an open-label, randomized clinical trial. BMC Res Notes. 2012;5:251.

24. Zhao Z, Cao X, Pan Y, Sha S, Zhao T, Zhang T. Simvastatin downregulates HER2 via upregulation of PEA3 to induce cell death in HER2positive breast cancer cells. Oncol Res. 2012;20(5-6):187-195. 
25. Shang L, Jia SS, Jiang HM, Wang H, Xu WH, Lv CJ. Simvastatin downregulates expression of TGF-betaRII and inhibits proliferation of A549 cells via ERK. Tumour Biol. 2015;36(6):4819-4824.

26. Williams AB, Li L, Nguyen B, Brown P, Levis M, Small D. Fluvastatin inhibits FLT3 glycosylation in human and murine cells and prolongs survival of mice with FLT3/ITD leukemia. Blood. 2012;120(15): 3069-3079.

27. Mira E, Carmona-Rodriguez L, Tardaguila M, et al. A lovastatinelicited genetic program inhibits M2 macrophage polarization and enhances $\mathrm{T}$ cell infiltration into spontaneous mouse mammary tumors. Oncotarget. 2013;4(12):2288-2301.

28. Liao J, Chung YT, Yang AL, et al. Atorvastatin inhibits pancreatic carcinogenesis and increases survival in LSL-KrasG12D-LSLTrp53R172H-Pdx1-Cre mice. Mol Carcinog. 2013;52(9):739-750.

29. Xu P, Yu H, Zhang Z, et al. Hydrogen-bonded and reductionresponsive micelles loading atorvastatin for therapy of breast cancer metastasis. Biomaterials. 2014;35(26):7574-7587.

30. Matusewicz L, Meissner J, Toporkiewicz M, Sikorski AF. The effect of statins on cancer cells-review. Tumour Biol. 2015;36(7):4889-4904.

31. Liu H, Wang Z, Li Y, Li W, Chen Y. Simvastatin prevents proliferation and bone metastases of lung adenocarcinoma in vitro and in vivo. Neoplasma. 2013;60(3):240-246.

32. Wang L, Yang H, Lei Z, et al. Repression of TIF1gamma by SOX2 promotes TGF-beta-induced epithelial-mesenchymal transition in nonsmall-cell lung cancer. Oncogene. 2016;35(7):867-877.

33. Li Y, Fu J, Yuan X, Hu C. Simvastatin inhibits the proliferation of A549 lung cancer cells through oxidative stress and up-regulation of SOD2. Die Pharmazie. 2014;69(8):610-614.

34. Yu X, Pan Y, Ma H, Li W. Simvastatin inhibits proliferation and induces apoptosis in human lung cancer cells. Oncol Res. 2013;20(8): 351-357.

35. Liang YW, Chang CC, Hung CM, Chen TY, Huang TY, Hsu YC. Preclinical activity of simvastatin induces cell cycle arrest in G1 via blockade of cyclin D-Cdk4 expression in Non-Small Cell Lung Cancer (NSCLC). Int J Mol Sci. 2013;14(3):5806-5816.

36. Spampanato C, De Maria S, Sarnataro M, et al. Simvastatin inhibits cancer cell growth by inducing apoptosis correlated to activation of Bax and down-regulation of BCL-2 gene expression. Int J Oncol. 2012; 40(4):935-941.

37. Ghosh-Choudhury N, Mandal CC, Ghosh-Choudhury N, Ghosh Choudhury G. Simvastatin induces derepression of PTEN expression via NFkappaB to inhibit breast cancer cell growth. Cell Signal. 2010; 22(5):749-758.

38. Mandal CC, Ghosh-Choudhury N, Yoneda T, Choudhury GG, GhoshChoudhury N. Simvastatin prevents skeletal metastasis of breast cancer by an antagonistic interplay between p53 and CD44. J Biol Chem. 2011; 286(13):11314-11327.

39. Wang $\mathrm{Z}$, Wu $\mathrm{Y}$, Wang $\mathrm{H}$, et al. Interplay of mevalonate and Hippo pathways regulates RHAMM transcription via YAP to modulate breast cancer cell motility. Proc Natl Acad Sci U S A. 2014;111(1): E89-E98.

40. Kotamraju S, Williams CL, Kalyanaraman B. Statin-induced breast cancer cell death: role of inducible nitric oxide and arginase-dependent pathways. Cancer Res. 2007;67(15):7386-7394.

41. Einbond LS, Wu HA, Sandu C, et al. Digitoxin enhances the growth inhibitory effects of thapsigargin and simvastatin on ER negative human breast cancer cells. Fitoterapia. 2016;109:146-154.

42. Liang Z, Li W, Liu J, et al. Simvastatin suppresses the DNA replication licensing factor MCM7 and inhibits the growth of tamoxifen-resistant breast cancer cells. Sci Rep. 2017;7:41776.

43. Lehn S, Ferno M, Jirstrom K, Ryden L, Landberg G. A non-functional retinoblastoma tumor suppressor $(\mathrm{RB})$ pathway in premenopausal breast cancer is associated with resistance to tamoxifen. Cell Cycle. 2011; 10(6):956-962.

44. Rogers M, Kalra S, Moukharskaya J, et al. Synergistic growth inhibition of PC3 prostate cancer cells with low-dose combinations of simvastatin and alendronate. Anticancer Res. 2015;35(4):1851-1859.
45. Nordstrand A, Lundholm M, Larsson A, Lerner UH, Widmark A, Wikstrom P. Inhibition of the insulin-like growth factor-1 receptor enhances effects of simvastatin on prostate cancer cells in co-culture with bone. Cancer Microenviron. 2013;6(3):231-240.

46. Al-Husein B, Goc A, Somanath PR. Suppression of interactions between prostate tumor cell-surface integrin and endothelial ICAM-1 by simvastatin inhibits micrometastasis. J Cell Physiol. 2013;228(11): 2139-2148.

47. Wang G, Cao R, Wang Y, et al. Simvastatin induces cell cycle arrest and inhibits proliferation of bladder cancer cells via PPARgamma signalling pathway. Sci Rep. 2016;6:35783.

48. Borahay MA, Kilic GS, Yallampalli C, et al. Simvastatin potently induces calcium-dependent apoptosis of human leiomyoma cells. J Biol Chem. 2014;289(51):35075-35086.

49. Cho SJ, Kim JS, Kim JM, Lee JY, Jung HC, Song IS. Simvastatin induces apoptosis in human colon cancer cells and in tumor xenografts, and attenuates colitis-associated colon cancer in mice. Int J Cancer. 2008; 123(4):951-957.

50. Jang HJ, Hong EM, Park SW, et al. Statin induces apoptosis of human colon cancer cells and downregulation of insulin-like growth factor 1 receptor via proapoptotic ERK activation. Oncol Lett. 2016;12(1):250-256.

51. de Llobet LI, Baro M, Mesia R, Balart J. Simvastatin enhances the effects of radiotherapy and cetuximab on a cell line $(\mathrm{FaDu})$ derived from a squamous cell carcinoma of head and neck. Transl Oncol. 2014;7(4): 513-522.

52. Fuchs D, Berges C, Opelz G, Daniel V, Naujokat C. HMG-CoA reductase inhibitor simvastatin overcomes bortezomib-induced apoptosis resistance by disrupting a geranylgeranyl pyrophosphate-dependent survival pathway. Biochem Biophys Res Commun. 2008;374(2):309-314.

53. Saito A, Saito N, Mol W, et al. Simvastatin inhibits growth via apoptosis and the induction of cell cycle arrest in human melanoma cells. Melanoma Res. 2008;18(2):85-94.

54. Glynn SA, O'Sullivan D, Eustace AJ, Clynes M, O'Donovan N. The 3-hydroxy-3-methylglutaryl-coenzyme A reductase inhibitors, simvastatin, lovastatin and mevastatin inhibit proliferation and invasion of melanoma cells. BMC Cancer. 2008;8:9.

55. Gronich N, Drucker L, Shapiro H, Radnay J, Yarkoni S, Lishner M. Simvastatin induces death of multiple myeloma cell lines. J Investig Med. 2004;52(5):335-344.

56. Schmidmaier R, Baumann P, Simsek M, Dayyani F, Emmerich B, Meinhardt G. The HMG-CoA reductase inhibitor simvastatin overcomes cell adhesion-mediated drug resistance in multiple myeloma by geranylgeranylation of Rho protein and activation of Rho kinase. Blood. 2004;104(6): 1825-1832.

57. Atil B, Berger-Sieczkowski E, Bardy J, Werner M, Hohenegger M. In vitro and in vivo downregulation of the ATP binding cassette transporter B1 by the HMG-CoA reductase inhibitor simvastatin. Naunyn Schmiedeberg's Arch Pharmacol. 2016;389(1):17-32.

58. Wolfe AR, Debeb BG, Lacerda L, et al. Simvastatin prevents triplenegative breast cancer metastasis in pre-clinical models through regulation of FOXO3a. Breast Cancer Res Treat. 2015;154(3):495-508.

59. Fang Z, Tang Y, Fang J, et al. Simvastatin inhibits renal cancer cell growth and metastasis via AKT/mTOR, ERK and JAK2/STAT3 pathway. PLoS One. 2013;8(5):e62823.

60. Alupei MC, Licarete E, Patras L, Banciu M. Liposomal simvastatin inhibits tumor growth via targeting tumor-associated macrophagesmediated oxidative stress. Cancer Lett. 2015;356(2 Pt B):946-952.

61. Coimbra M, Banciu M, Fens MH, et al. Liposomal pravastatin inhibits tumor growth by targeting cancer-related inflammation. $J$ Control Release. 2010;148(3):303-310.

62. Lee SJ, Lee I,Lee J, Park C, Kang WK. Statins, 3-hydroxy-3-methylglutaryl coenzyme A reductase inhibitors, potentiate the anti-angiogenic effects of bevacizumab by suppressing angiopoietin2, BiP, and Hsp90alpha in human colorectal cancer. Br J Cancer. 2014;111(3):497-505.

63. Li G, Zheng J, Xu B, Ling J, Qiu W, Wang Y. Simvastatin inhibits tumor angiogenesis in HER2-overexpressing human colorectal cancer. Biomed Pharmacother. 2017;85:418-424. 
64. Cohen JI. HMG CoA reductase inhibitors (statins) to treat Epstein-Barr virus-driven lymphoma. Br J Cancer. 2005;92(9):1593-1598.

65. Inano H, Suzuki K, Onoda M, Wakabayashi K. Anti-carcinogenic activity of simvastatin during the promotion phase of radiation-induced mammary tumorigenesis of rats. Carcinogenesis. 1997;18(9):1723-1727.

66. Clutterbuck RD, Millar BC, Powles RL, et al. Inhibitory effect of simvastatin on the proliferation of human myeloid leukaemia cells in severe combined immunodeficient (SCID) mice. Br J Haematol. 1998; 102(2):522-527.

67. Erbas H, Bal O, Cakir E. Effect of rosuvastatin on arginase enzyme activity and polyamine production in experimental breast cancer. Balkan Med J. 2015;32(1):89-95.

68. Polat MF, Taysi S, Polat S, Boyuk A, Bakan E. Elevated serum arginase activity levels in patients with breast cancer. Surg Today. 2003; 33(9):655-661.

69. Morris SM Jr. Arginine metabolism: boundaries of our knowledge. J Nutr. 2007;137(6 Suppl 2):1602s-1609s.

70. Nowotarski SL, Woster PM, Casero RA Jr. Polyamines and cancer: implications for chemotherapy and chemoprevention. Expert Rev Mol Med. 2013;15:e3.

71. Plunkett W. Arginine addiction in AML. Blood. 2015;125(26): 3971-3972.

72. Narisawa T, Fukaura Y, Tanida N, Hasebe M, Ito M, Aizawa R. Chemopreventive efficacy of low dose of pravastatin, an HMG-CoA reductase inhibitor, on 1,2-dimethylhydrazine-induced colon carcinogenesis in ICR mice. Tohoku J Exp Med. 1996;180(2):131-138.

73. Narisawa T, Morotomi M, Fukaura Y, Hasebe M, Ito M, Aizawa R. Chemoprevention by pravastatin, a 3-hydroxy-3-methylglutaryl-coenzyme A reductase inhibitor, of N-methyl-N-nitrosourea-induced colon carcinogenesis in F344 rats. Jpn J Cancer Res. 1996;87(8):798-804.

74. Shellman YG, Ribble D, Miller L, et al. Lovastatin-induced apoptosis in human melanoma cell lines. Melanoma Res. 2005;15(2):83-89.

75. Dimitroulakos J, Yeger H. HMG-CoA reductase mediates the biological effects of retinoic acid on human neuroblastoma cells: lovastatin specifically targets P-glycoprotein-expressing cells. Nat Med. 1996;2(3): 326-333.

76. Rubins JB, Greatens T, Kratzke RA, Tan AT, Polunovsky VA, Bitterman P. Lovastatin induces apoptosis in malignant mesothelioma cells. Am J Respir Crit Care Med. 1998;157(5 Pt 1):1616-1622.

77. Dimitroulakos J, Nohynek D, Backway KL, et al. Increased sensitivity of acute myeloid leukemias to lovastatin-induced apoptosis: A potential therapeutic approach. Blood. 1999;93(4):1308-1318.

78. Macaulay RJ, Wang W, Dimitroulakos J, Becker LE, Yeger H. Lovastatin-induced apoptosis of human medulloblastoma cell lines in vitro. $J$ Neurooncol. 1999;42(1):1-11.

79. Dimitroulakos J, Ye LY, Benzaquen M, et al. Differential sensitivity of various pediatric cancers and squamous cell carcinomas to lovastatin-induced apoptosis: therapeutic implications. Clin Cancer Res. 2001;7(1): $158-167$.

80. Ogunwobi OO, Beales IL. Statins inhibit proliferation and induce apoptosis in Barrett's esophageal adenocarcinoma cells. Am J Gastroenterol. 2008;103(4):825-837.

81. Maksimova E, Yie TA, Rom WN. In vitro mechanisms of lovastatin on lung cancer cell lines as a potential chemopreventive agent. Lung. 2008;186(1):45-54.

82. Park IH, Kim JY, Jung JI, Han JY. Lovastatin overcomes gefitinib resistance in human non-small cell lung cancer cells with K-Ras mutations. Invest New Drugs. 2010;28(6):791-799.

83. Jeon JH, Kim SK, Kim HJ, Chang J, Ahn CM, Chang YS. Lipid raft modulation inhibits NSCLC cell migration through delocalization of the focal adhesion complex. Lung Cancer. 2010;69(2):165-171.

84. Zhang X, Teng Y, Yang F, et al. MCM2 is a therapeutic target of lovastatin in human non-small cell lung carcinomas. Oncol Rep. 2015; 33(5):2599-2605.

85. Agarwal B, Bhendwal S, Halmos B, Moss SF, Ramey WG, Holt PR. Lovastatin augments apoptosis induced by chemotherapeutic agents in colon cancer cells. Clin Cancer Res. 1999;5(8):2223-2229.
86. Swamy MV, Cooma I, Reddy BS, Rao CV. Lamin B, caspase- 3 activity, and apoptosis induction by a combination of HMG-CoA reductase inhibitor and COX-2 inhibitors: a novel approach in developing effective chemopreventive regimens. Int J Oncol. 2002;20(4): 753-759.

87. Mantha AJ, Hanson JE, Goss G, Lagarde AE, Lorimer IA, Dimitroulakos J. Targeting the mevalonate pathway inhibits the function of the epidermal growth factor receptor. Clin Cancer Res. 2005; 11(6):2398-2407.

88. Hoque A, Chen H, Xu XC. Statin induces apoptosis and cell growth arrest in prostate cancer cells. Cancer Epidemiol Biomarkers Prev. 2008;17(1):88-94.

89. Park C, Lee I, Kang WK. Lovastatin-induced E2F-1 modulation and its effect on prostate cancer cell death. Carcinogenesis. 2001;22(10): $1727-1731$.

90. Afshordel S, Kern B, Clasohm J, et al. Lovastatin and perillyl alcohol inhibit glioma cell invasion, migration, and proliferation - impact of Ras-/Rho-prenylation. Pharmacol Res. 2015;91:69-77.

91. Glodkowska-Mrowka E, Mrowka P, Basak GW, et al. Statins inhibit $\mathrm{ABCB} 1$ and $\mathrm{ABCG} 2$ drug transporter activity in chronic myeloid leukemia cells and potentiate antileukemic effects of imatinib. Exp Hematol. 2014;42(6):439-447.

92. Song X, Liu BC, Lu XY, et al. Lovastatin inhibits human B lymphoma cell proliferation by reducing intracellular ROS and TRPC6 expression. Biochim Biophys Acta. 2014;1843(5):894-901.

93. Yang $\mathrm{T}$, Yao $\mathrm{H}, \mathrm{He} \mathrm{G}$, et al. Effects of lovastatin on MDA-MB-231 breast cancer cells: an antibody microarray analysis. $J$ Cancer. 2016;7(2): 192-199.

94. Holstein SA, Hohl RJ. Interaction of cytosine arabinoside and lovastatin in human leukemia cells. Leuk Res. 2001;25(8):651-660.

95. Zhao TT, Le Francois BG, Goss G, Ding K, Bradbury PA, Dimitroulakos J. Lovastatin inhibits EGFR dimerization and AKT activation in squamous cell carcinoma cells: potential regulation by targeting rho proteins. Oncogene. 2010;29(33):4682-4692.

96. Weitberg AB. The antioxidant effect of lovastatin on phagocyteinduced DNA damage: implications for cancer prevention. J Exp Clin Cancer Res. 2007;26(4):583-586.

97. Ajith TA, Soja M. A comparative study on the antimutagenicity of atorvastatin and lovastatin against directly acting mutagens. Cell Biol Toxicol. 2006;22(4):269-274.

98. Feleszko W, Zagozdzon R, Golab J, Jakobisiak M. Potentiated antitumour effects of cisplatin and lovastatin against MmB16 melanoma in mice. Eur J Cancer. 1998;34(3):406-411.

99. Feleszko W, Balkowiec EZ, Sieberth E, et al. Lovastatin and tumor necrosis factor-alpha exhibit potentiated antitumor effects against Ha-ras-transformed murine tumor via inhibition of tumor-induced angiogenesis. Int J Cancer. 1999;81(4):560-567.

100. Ajith TA, Harikumar KB, Thasna H, Sabu MC, Babitha NV. Proapoptotic and antitumor activities of the HMG-CoA reductase inhibitor, lovastatin, against Dalton's lymphoma ascites tumor in mice. Clin Chim Acta. 2006;366(1-2):322-328.

101. Matar P, Rozados VR, Roggero EA, Scharovsky OG. Lovastatin inhibits tumor growth and metastasis development of a rat fibrosarcoma. Cancer Biother Radiopharm. 1998;13(5):387-393.

102. Matar P, Rozados VR, Binda MM, Roggero EA, Bonfil RD, Scharovsky OG. Inhibitory effect of Lovastatin on spontaneous metastases derived from a rat lymphoma. Clin Exp Metastasis. 1999; 17(1):19-25.

103. Jani JP, Specht S, Stemmler N, et al. Metastasis of B16F10 mouse melanoma inhibited by lovastatin, an inhibitor of cholesterol biosynthesis. Invasion Metastasis. 1993;13(6):314-324.

104. Alo PL, Visca P, Marci A, Mangoni A, Botti C, Di Tondo U. Expression of fatty acid synthase (FAS) as a predictor of recurrence in stage I breast carcinoma patients. Cancer. 1996;77(3):474-482.

105. Hawk MA, Cesen KT, Siglin JC, Stoner GD, Ruch RJ. Inhibition of lung tumor cell growth in vitro and mouse lung tumor formation by lovastatin. Cancer Lett. 1996;109(1-2):217-222. 
106. Ding N, Cui XX, Gao Z, et al. A triple combination of atorvastatin, celecoxib and tipifarnib strongly inhibits pancreatic cancer cells and xenograft pancreatic tumors. Int J Oncol. 2014;44(6):2139-2145.

107. Islam M, Sharma S, Kumar B, Teknos TN. Atorvastatin inhibits RhoC function and limits head and neck cancer metastasis. Oral Oncol. 2013;49(8):778-786.

108. Fan Z, Jiang H, Wang Z, Qu J. Atorvastatin partially inhibits the epithelial-mesenchymal transition in A549 cells induced by TGF-beta1 by attenuating the upregulation of SphK1. Oncol Rep. 2016;36(2) 1016-1022.

109. Ghalali A, Wiklund F, Zheng H, Stenius U, Hogberg J. Atorvastatin prevents ATP-driven invasiveness via P2X7 and EHBP1 signaling in PTEN-expressing prostate cancer cells. Carcinogenesis. 2014;35(7): $1547-1555$

110. Alderton GK. Tumour immunology: suppressing tumorigenic inflammation. Nat Rev Cancer. 2012;12(4):228.

111. Briso EM, Guinea-Viniegra J, Bakiri L, et al. Inflammation-mediated skin tumorigenesis induced by epidermal c-Fos. Genes Dev. 2013; 27(18):1959-1973

112. Suh N, Reddy BS, DeCastro A, et al. Combination of atorvastatin with sulindac or naproxen profoundly inhibits colonic adenocarcinomas by suppressing the $\mathrm{p} 65 /$ beta-catenin/cyclin D1 signaling pathway in rats. Cancer Prev Res (Phila). 2011;4(11):1895-1902.

113. Zheng X, Cui XX, Avila GE, et al. Atorvastatin and celecoxib inhibit prostate PC-3 tumors in immunodeficient mice. Clin Cancer Res. 2007; 13(18 Pt 1):5480-5487.

114. Zheng X, Cui XX, Gao Z, et al. Atorvastatin and celecoxib in combination inhibits the progression of androgen-dependent LNCaP xenograft prostate tumors to androgen independence. Cancer Prev Res (Phila) 2010;3(1):114-124.

115. Swamy MV, Patlolla JM, Steele VE, Kopelovich L, Reddy BS, Rao CV. Chemoprevention of familial adenomatous polyposis by low doses of atorvastatin and celecoxib given individually and in combination to APCMin mice. Cancer Res. 2006;66(14):7370-7377.

116. Shachaf CM, Perez OD, Youssef S, et al. Inhibition of HMGcoA reductase by atorvastatin prevents and reverses $\mathrm{MYC}$-induced lymphomagenesis. Blood. 2007;110(7):2674-2684.

117. Slawinska-Brych A, Zdzisinska B, Kandefer-Szerszen M. Fluvastatin inhibits growth and alters the malignant phenotype of the C6 glioma cell line. Pharmacol Rep. 2014;66(1):121-129.

118. Sassano A, Katsoulidis E, Antico G, et al. Suppressive effects of statins on acute promyelocytic leukemia cells. Cancer Res. 2007;67(9): 4524-4532.

119. Woodard J, Sassano A, Hay N, Platanias LC. Statin-dependent suppression of the Akt/mammalian target of rapamycin signaling cascade and programmed cell death 4 up-regulation in renal cell carcinoma. Clin Cancer Res. 2008;14(14):4640-4649.

120. Kusama T, Mukai M, Iwasaki T, et al. Inhibition of epidermal growth factor-induced RhoA translocation and invasion of human pancreatic cancer cells by 3-hydroxy-3-methylglutaryl-coenzyme a reductase inhibitors. Cancer Res. 2001;61(12):4885-4891.

121. Takahashi HK, Weitz-Schmidt G, Iwagaki H, Yoshino T, Tanaka N, Nishibori M. Hypothesis: the antitumor activities of statins may be mediated by IL-18. J Leukocyte Biol. 2006;80(2):215-216.

122. Horiguchi A, Sumitomo M, Asakuma J, Asano T, Asano T, Hayakawa M. 3-hydroxy-3-methylglutaryl-coenzyme a reductase inhibitor, fluvastatin, as a novel agent for prophylaxis of renal cancer metastasis. Clin Cancer Res. 2004;10(24):8648-8655.

123. Thibault A, Samid D, Tompkins AC, et al. Phase I study of lovastatin, an inhibitor of the mevalonate pathway, in patients with cancer. Clin Cancer Res. 1996;2(3):483-491.

124. Larner J, Jane J, Laws E, Packer R, Myers C, Shaffrey M. A phase I-II trial of lovastatin for anaplastic astrocytoma and glioblastoma multiforme. Am J Clin Oncol. 1998;21(6):579-583.

125. Kim WS, Kim MM, Choi HJ, et al. Phase II study of high-dose lovastatin in patients with advanced gastric adenocarcinoma. Invest New Drugs. 2001;19(1):81-83.
126. Kawata S, Yamasaki E, Nagase T, et al. Effect of pravastatin on survival in patients with advanced hepatocellular carcinoma. A randomized controlled trial. Br J Cancer. 2001;84(7):886-891.

127. Graf H, Jungst C, Straub G, et al. Chemoembolization combined with pravastatin improves survival in patients with hepatocellular carcinoma. Digestion. 2008;78(1):34-38.

128. Lee J, Jung KH, Park YS, et al. Simvastatin plus irinotecan, 5-fluorouracil, and leucovorin (FOLFIRI) as first-line chemotherapy in metastatic colorectal patients: a multicenter phase II study. Cancer Chemother Pharmacol. 2009;64(4):657-663.

129. Baas JM, Krens LL, ten Tije AJ, et al. Safety and efficacy of the addition of simvastatin to cetuximab in previously treated KRAS mutant metastatic colorectal cancer patients. Invest New Drugs. 2015 ; 33(6):1242-1247.

130. Baas JM, Krens LL, Bos MM, et al. Safety and efficacy of the addition of simvastatin to panitumumab in previously treated KRAS mutant metastatic colorectal cancer patients. Anticancer Drugs. 2015;26(8): 872-877.

131. Krens LL, Simkens LH, Baas JM, et al. Statin use is not associated with improved progression free survival in cetuximab treated KRAS mutant metastatic colorectal cancer patients: results from the CAIRO2 study. PLoS One. 2014;9(11):e112201.

132. Nielsen SF, Nordestgaard BG, Bojesen SE. Statin use and reduced cancer-related mortality. N Engl J Med. 2013;368(6):576-577.

133. Klop C, Driessen JH, de Vries F. Statin use and reduced cancer-related mortality. N Engl J Med. 2013;368(6):574.

134. Kopel E, Maor E, Goldenberg I. Statin use and reduced cancer-related mortality. N Engl J Med. 2013;368(6):575-576.

135. Brewer TM, Masuda H, Liu DD, et al. Statin use in primary inflammatory breast cancer: a cohort study. Br J Cancer. 2013;109(2): 318-324.

136. Bjarnadottir O, Romero Q, Bendahl PO, et al. Targeting HMG-CoA reductase with statins in a window-of-opportunity breast cancer trial Breast Cancer Res Treat. 2013;138(2):499-508.

137. Bjarnadottir O, Kimbung S, Johansson I, et al. Global transcriptional changes following statin treatment in breast cancer. Clin Cancer Res. 2015;21(15):3402-3411.

138. Feldt M, Bjarnadottir O, Kimbung S, et al. Statin-induced antiproliferative effects via cyclin D1 and p27 in a window-of-opportunity breast cancer trial. J Transl Med. 2015;13:133.

139. Garwood ER, Kumar AS, Baehner FL, et al. Fluvastatin reduces proliferation and increases apoptosis in women with high grade breast cancer. Breast Cancer Res Treat. 2010;119(1):137-144.

140. Wang A, Stefanick ML, Kapphahn K, et al. Relation of statin use with non-melanoma skin cancer: prospective results from the Women's Health Initiative. Br J Cancer. 2016;114(3):314-320.

141. Randomised trial of cholesterol lowering in 4444 patients with coronary heart disease: the Scandinavian Simvastatin Survival Study (4S). Lancet. 1994;344(8934):1383-1389.

142. MRC/BHF Heart Protection Study of cholesterol lowering with simvastatin in 20,536 high-risk individuals: a randomised placebocontrolled trial. Lancet. 2002;360(9326):7-22.

143. Kuoppala J, Lamminpaa A, Pukkala E. Statins and cancer: a systematic review and meta-analysis. Eur J Cancer. 2008;44(15):2122-2132.

144. Arnspang S, Pottegard A, Friis S, et al. Statin use and risk of nonmelanoma skin cancer: a nationwide study in Denmark. Br J Cancer. 2015;112(1):153-156.

145. Blais L, Desgagne A, LeLorier J. 3-Hydroxy-3-methylglutaryl coenzyme A reductase inhibitors and the risk of cancer: a nested casecontrol study. Arch Intern Med. 2000;160(15):2363-2368.

146. Graaf MR, Beiderbeck AB, Egberts AC, Richel DJ, Guchelaar HJ The risk of cancer in users of statins. J Clin Oncol. 2004;22(12): 2388-2394.

147. Peto R, Emberson J, Landray M, et al. Analyses of cancer data from three ezetimibe trials. $N$ Engl J Med. 2008;359(13):1357-1366.

148. Bjerre LM, LeLorier J. Do statins cause cancer? A meta-analysis of large randomized clinical trials. Am J Med. 2001;110(9):716-723. 
149. Asgari MM, Tang J, Epstein EH, Jr, et al. Statin use and risk of basal cell carcinoma. J Am Acad Dermatol. 2009;61(1):66-72.

150. Haukka J, Sankila R, Klaukka T, et al. Incidence of cancer and statin usage-record linkage study. Int J Cancer. 2010;126(1):279-284.

151. Li X, Wu XB, Chen Q. Statin use is not associated with reduced risk of skin cancer: a meta-analysis. Br J Cancer. 2014;110(3):802-807.

152. Lim SH, Kim TW, Hong YS, et al. A randomised, double-blind, placebo-controlled multi-centre phase III trial of XELIRI/FOLFIRI plus simvastatin for patients with metastatic colorectal cancer. $\mathrm{Br} J$ Cancer. 2015;113(10):1421-1426.

153. Wallace A, Chinn D, Rubin G. Taking simvastatin in the morning compared with in the evening: randomised controlled trial. $B M J$. 2003;327(7418):788.

154. Drazen JM, D'Agostino RB, Ware JH, Morrissey S, Curfman GD. Ezetimibe and cancer-an uncertain association. N Engl J Med. 2008; 359(13):1398-1399.

155. Rossebo AB, Pedersen TR, Boman K, et al. Intensive lipid lowering with simvastatin and ezetimibe in aortic stenosis. $N$ Engl J Med. 2008; 359(13):1343-1356.

156. Green A, Ramey DR, Emneus M, et al. Incidence of cancer and mortality in patients from the Simvastatin and Ezetimibe in Aortic Stenosis (SEAS) trial. Am J Cardiol. 2014;114(10):1518-1522.

157. Marcelli M, Cunningham GR, Haidacher SJ, et al. Caspase-7 is activated during lovastatin-induced apoptosis of the prostate cancer cell line LNCaP. Cancer Res. 1998;58(1):76-83.

158. Gbelcova H, Lenicek M, Zelenka J, et al. Differences in antitumor effects of various statins on human pancreatic cancer. Int J Cancer. 2008;122(6):1214-1221.

159. Burke LP, Kukoly CA. Statins induce lethal effects in acute myeloblastic leukemia [corrected] cells within 72 hours. Leuk Lymphoma. 2008;49(2):322-330.

160. Prasanna P, Thibault A, Liu L, Samid D. Lipid metabolism as a target for brain cancer therapy: synergistic activity of lovastatin and sodium phenylacetate against human glioma cells. J Neurochem. 1996; 66(2):710-716

161. Kornbrust DJ, MacDonald JS, Peter CP, et al. Toxicity of the HMGcoenzyme A reductase inhibitor, lovastatin, to rabbits. J Pharmacol Exp Ther. 1989;248(2):498-505.

162. Feleszko W, Mlynarczuk I, Balkowiec-Iskra EZ, et al. Lovastatin potentiates antitumor activity and attenuates cardiotoxicity of doxorubicin in three tumor models in mice. Clin Cancer Res. 2000;6(5): 2044-2052.

163. Lishner M, Bar-Sef A, Elis A, Fabian I. Effect of simvastatin alone and in combination with cytosine arabinoside on the proliferation of myeloid leukemia cell lines. J Investig Med. 2001;49(4):319-324.

164. Lee J, Lee I, Han B, et al. Effect of simvastatin on cetuximab resistance in human colorectal cancer with KRAS mutations. J Natl Cancer Inst. 2011;103(8):674-688.

165. Xiao H, Yang CS. Combination regimen with statins and NSAIDs: a promising strategy for cancer chemoprevention. Int J Cancer. 2008;123(5):983-990.

166. Maron DJ, Fazio S, Linton MF. Current perspectives on statins. Circulation. 2000;101(2):207-213.

167. Farmer JA, Torre-Amione G. Comparative tolerability of the HMGCoA reductase inhibitors. Drug Safety. 2000;23(3):197-213.

168. Nawarskas JJ. HMG-CoA reductase inhibitors and coenzyme Q10. Cardiology Rev. 2005;13(2):76-79.

169. Williams D, Feely J. Pharmacokinetic-pharmacodynamic drug interactions with HMG-CoA reductase inhibitors. Clin Pharmacokinet. 2002;41(5):343-370

170. Molden E, Andersson KS. Simvastatin-associated rhabdomyolysis after coadministration of macrolide antibiotics in two patients. Pharmacotherapy. 2007;27(4):603-607.

171. Batchelor TT, Taylor LP, Thaler HT, Posner JB, DeAngelis LM. Steroid myopathy in cancer patients. Neurology. 1997;48(5):1234-1238.

172. Gopaluni S, Thomas LM, Shah C. When myopathy strikes in a cancer patient. Gastrointest Cancer Res: GCR. 2009;3(5):212-214.
173. Troyanov Y, Landon-Cardinal O, Fritzler MJ, et al. Atorvastatininduced necrotizing autoimmune myositis: An emerging dominant entity in patients with autoimmune myositis presenting with a pure polymyositis phenotype. Medicine (Baltimore). 2017;96(3): e5694.

174. Tellier P. L'ezetimibe : de la pharmacologie aux essais thérapeutiques [Ezetimibe: from pharmacology to clinical trials]. Ann Endocrinol (Paris). 2003;64(6):442-447. French.

175. Jeu L, Cheng JW. Pharmacology and therapeutics of ezetimibe (SCH 58,235), a cholesterol-absorption inhibitor. Clin Ther. 2003; 25(9):2352-2387.

176. Yatskar L, Fisher EA, Schwartzbard A. Ezetimibe: rationale and role in the management of hypercholesterolemia. Clin Cardiol. 2006; 29(2):52-55.

177. Fraunberger P, Grone E, Grone HJ, Drexel H, Walli AK. Ezetimibe reduces cholesterol content and NF-kappaB activation in liver but not in intestinal tissue in guinea pigs. $J$ Inflamm (London). 2017; $14: 3$.

178. Sakurai T, Higashitsuji $\mathrm{H}$, Kashida $\mathrm{H}$, et al. The oncoprotein gankyrin promotes the development of colitis-associated cancer through activation of STAT3. Oncotarget. 2017;8(15):24762-24776.

179. Assaraf YG. Molecular basis of antifolate resistance. Cancer Metastasis Rev. 2007;26(1):153-181.

180. Oronsky BT, Reid T, Knox SJ, Scicinski JJ. The scarlet letter of alkylation: a mini review of selective alkylating agents. Transl Oncol. 2012;5(4):226-229.

181. Yared JA, Tkaczuk KH. Update on taxane development: new analogs and new formulations. Drug Des Devel Ther. 2012;6:371-384.

182. Brown C. Targeted therapy: an elusive cancer target. Nature. 2016; 537(7620):S106-S108.

183. Warburg O. On the origin of cancer cells. Science (New York, NY). 1956;123(3191):309-314.

184. Buchwald H. Cholesterol inhibition, cancer, and chemotherapy. Lancet (London, England). 1992;339(8802):1154-1156.

185. Cruz PM, Mo H, McConathy WJ, Sabnis N, Lacko AG. The role of cholesterol metabolism and cholesterol transport in carcinogenesis: a review of scientific findings, relevant to future cancer therapeutics. Front Pharmacol. 2013;4:119.

186. Aune D, Keum N, Giovannucci E, et al. Whole grain consumption and risk of cardiovascular disease, cancer, and all cause and cause specific mortality: systematic review and dose-response meta-analysis of prospective studies. BMJ. 2016;353:i2716.

187. Shi C, Zhang N, Feng Y, Cao J, Chen X, Liu B. Aspirin inhibits IKK-beta-mediated prostate cancer cell invasion by targeting matrix metalloproteinase-9 and Urokinase-type plasminogen activator. Cell Physiol Biochem. 2017;41(4):1313-1324.

188. Jiang J, Lan YQ, Zhang T, et al. The in vitro effects of caffeine on viability, cycle cycle profiles, proliferation, and apoptosis of glioblastomas. Eur Rev Med Pharmacol Sci. 2015;19(17):3201-3207.

189. Dong S, Kong J, Kong J, et al. Low concentration of caffeine inhibits the progression of the hepatocellular carcinoma via Akt signaling pathway. Anticancer Agents Med Chem. 2015;15(4):484-492.

190. Chen Y, Chou WC, Ding YM, Wu YC. Caffeine inhibits migration in glioma cells through the ROCK-FAK pathway. Cell Physiol Biochem. 2014;33(6):1888-1898.

191. Liu L, Liu J, Dai S, et al. Reduced transthyretin expression in sera of lung cancer. Cancer Sci. 2007;98(10):1617-1624.

192. Noy N, Li L, Abola MV, Berger NA. Is retinol binding protein 4 a link between adiposity and cancer? Horm Mol Biol Clin Investig. 2015;23(2):39-46.

193. Zhao C, Annamalai L, Guo C, et al. Circulating haptoglobin is an independent prognostic factor in the sera of patients with epithelial ovarian cancer. Neoplasia. 2007;9(1):1-7.

194. Zamanian-Daryoush M, DiDonato JA. Apolipoprotein A-I and cancer. Front Pharmacol. 2015;6:265.

195. Maree AO, Fitzgerald DJ. Aspirin and coronary artery disease. Thromb Haemost. 2004;92(6):1175-1181. 
196. Barrett PJ, Casey EK, Sisung C, Gaebler-Spira D. Caffeine as a neurostimulant: Two pediatric acquired brain injury cases. J Pediatr Rehabil Med. 2010;3(3):229-232.

197. Tazzeo T, Bates G, Roman HN, et al. Caffeine relaxes smooth muscle through actin depolymerization. Am J Physiol Lung Cell Mol Physiol. 2012;303(4):L334-L342.

198. Kolahdouzan M, Hamadeh MJ. The neuroprotective effects of caffeine in neurodegenerative diseases. CNS Neurosci Ther. 2017; 23(4):272-290.

199. Engelhardt G, Mauz AB, Pairet M. Role of caffeine in combined analgesic drugs from the point of view of experimental pharmacology. Arzneimittelforschung. 1997;47(8):917-927.

200. Pini LA, Guerzoni S, Cainazzo M, Ciccarese M, Prudenzano MP, Livrea P. Comparison of tolerability and efficacy of a combination of paracetamol + caffeine and sumatriptan in the treatment of migraine attack: a randomized, double-blind, double-dummy, cross-over study. J Headache Pain. 2012;13(8):669-675.
201. Cortez D. Caffeine inhibits checkpoint responses without inhibiting the ataxia-telangiectasia-mutated (ATM) and ATM- and Rad3-related (ATR) protein kinases. J Biol Chem. 2003;278(39):37139-37145.

202. Kim YM, Lee EJ, Park SY, Cho KH, Kim JY, Pyo H. Cyclooxygenase-2 up-regulates ataxia telangiectasia and Rad3 related through extracellular signal-regulated kinase activation. Mol Cancer Res. 2009;7(7):1158-1168.

203. Zhu W, Depamphilis ML. Selective killing of cancer cells by suppression of geminin activity. Cancer Res. 2009;69(11):4870-4877. 


\section{Supplementary material}

A

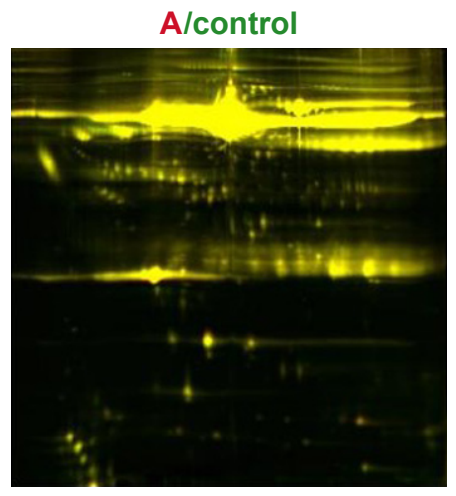

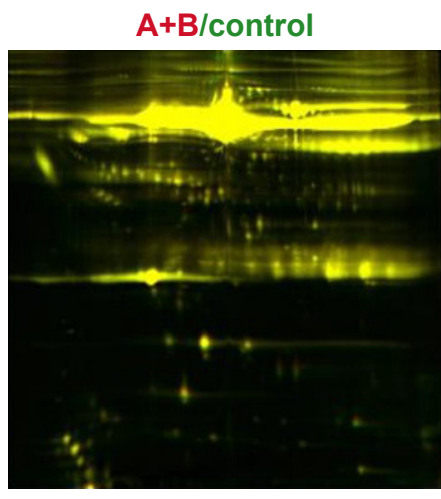

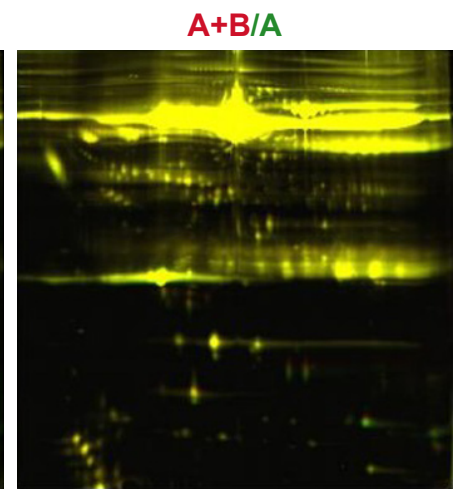

B

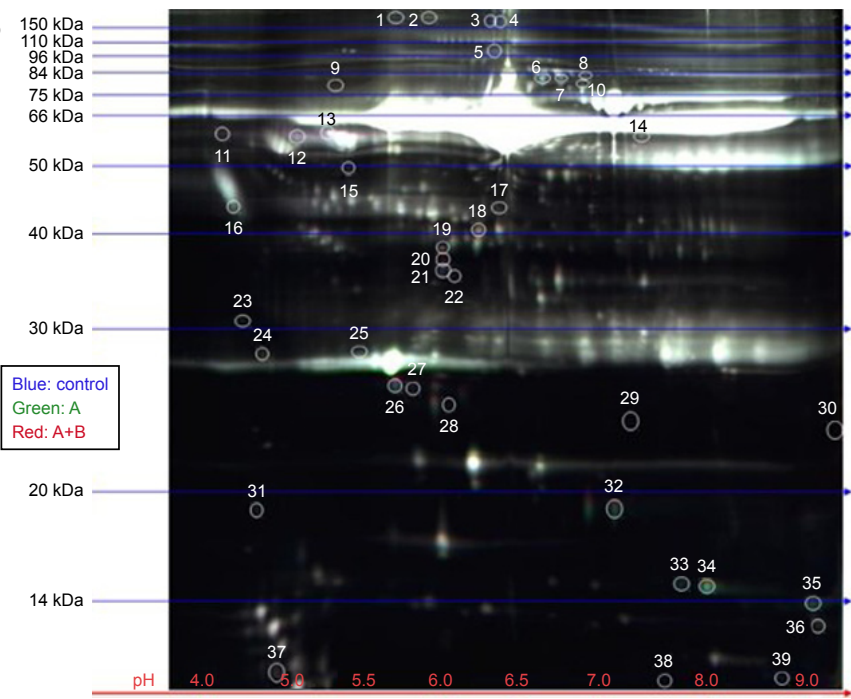

C

\begin{tabular}{|l|l|l|l|}
\hline \multirow{2}{*}{$\begin{array}{l}\text { Assigned ID/ } \\
\text { protein ID }\end{array}$} & \multicolumn{3}{|l|}{ Protein expression ratio } \\
\cline { 2 - 4 } & A/control & A+B/control & A+B/A \\
\hline $20(\mathrm{TTR})$ & 1,24 & 4,38 & 3,5 \\
$27(\mathrm{RBP} 4)$ & $-1,43$ & 1,07 & 1,5 \\
$30(\mathrm{Hp})$ & 1,85 & 3,2 & 1,71 \\
$39(\mathrm{ApoA} 1)$ & $-1,32$ & $-2,73$ & $-2,1$ \\
\hline
\end{tabular}

Figure SI Proteome profiling indicating alterations in the expression levels of human proteins evoked by the consumption of aspirin alone or combined with caffeine at clinically attainable doses.

Notes: Proteomic analysis in the serum of a 33-year-old healthy female individual 16 hours after the consumption of $500 \mathrm{mg}$ of a marketed (ASPIRIN 500MG/TAB, Bayer Hellas A.B.E.E., Marousi I5I 25, Attiki, Greece) tablet of aspirin ("A") or a marketed (KALMALINE AC [500+30]MG/TAB, Coup A.B.E.E., Agias Varvaras 53, P.C. I7235 Athens, Greece) tablet containing $500 \mathrm{mg}$ of aspirin and $30 \mathrm{mg}$ of caffeine ("A+B"). None of these pharmacologic agents or even a placebo pill was consumed by the volunteer in the case of "control" serum analysis, while the individual voluntarily did not consume any food or beverage containing caffeine (chocolate, tea and so on) at least 24 hours before any of the three distinct blood sample collections, which took place throughout a 3-day period (ie, Ist, 2nd and 3rd days when control, sample A and sample A+B were collected). Approximately $8 \mathrm{~mL}$ of blood was collected in serum separating tubes (BD Vacutainer SST II $8.5 \mathrm{~mL}$ Advance Tubes-367958; Scientific Diagnostics Ltd, Attiki, Greece), and $2 \mathrm{~mL}$ of serum obtained after sample centrifugation for $15 \mathrm{~min}$ at 3,000 rpm was transferred into cryovials (Greiner Bio-One GmbH $5 \mathrm{~mL}$ U-Bottom cryovials CE-IVD; Bioline Scientific, Athens, Greece) and stored at $-20^{\circ} \mathrm{C}$, until their transfer in dry ice shortly after (I day) the completion of the 3-day sample collecting period. All the experimental procedures associated with 2D-DIGE from protein extraction and sample labeling with CyDye DIGE fluors (blue, green and red for "Control", "A" and "A+B" samples, respectively) to spot picking and protein identification by mass spectrometry were performed at Applied Biomics (Hayward, CA, USA) according to the established protocol as it has been described elsewhere.' Shown here (A) are 2D-DIGE gel images from overlay of each paired sample, A/control, A+B/control and A+B/A. The protein spots shown in yellow color means that protein expression is similar in the paired samples (two-color image overlay). White color (B) means that the protein expression is the same in all these samples (three-color image overlay). For the aforementioned three paired comparisons, a fold $\geq 1.3$ was used as a cut-off value in the DeCyder analysis and most significant changed spots were selected. All the 39 spots were circled and numbered in the triple color overlay gel image with the estimated MW and isoelectric point (pl) grid (C). Each spot number was assigned (Assigned ID/protein ID) if the ratio of changes in at least one paired sample was $\geq 1.3$ fold. Some of the statistically significant spot ratios corresponding to the expression of the 15 proteins which were mostly affected (either positively or negatively) in the $A+B / A$ paired sample were chosen for identification by mass spectrometry. The rationale for focusing on this category of proteins is based on the fact that these proteins indicate the differential biologic outcome of aspirin when it is received in combination with caffeine ("A+B" or the numerator of the fraction) or not ("A" or the denominator of the fraction), respectively. Mass spectrometry revealed that the ID of four randomly chosen spots (C, shown as boxed values of the "A+B" paired sample) corresponding to the 15 most influenced proteins in the $A+B / A$ paired sample is TTR (protein expression ratio 3, 5, spot number 20), RBP4 (protein expression ratio I, 5, spot number 27), Hp (protein expression ratio I, 7I, spot number 30) and ApoAI (protein expression ratio -2, I, spot number 39). The role of these proteins in tumorigenesis and/or cancer diagnosis/prognosis is discussed in the text.

Abbreviations: 2D-DIGE, two-dimensional difference in gel electrophoresis; ApoAI, apolipoprotein AI; Hp, haptoglobin; MW, molecular weight; TTR, transthyretin; RBP4, retinol-binding protein 4.

\section{Reference}

1. Clement CC, Cannizzo ES, Nastke MD, et al. An expanded self-antigen peptidome is carried by the human lymph as compared to the plasma. PLoS One. 2010;5(3):e9863. 
OncoTargets and Therapy

\section{Publish your work in this journal}

OncoTargets and Therapy is an international, peer-reviewed, open access journal focusing on the pathological basis of all cancers, potential targets for therapy and treatment protocols employed to improve the management of cancer patients. The journal also focuses on the impact of management programs and new therapeutic agents and protocols on

patient perspectives such as quality of life, adherence and satisfaction. The manuscript management system is completely online and includes a very quick and fair peer-review system, which is all easy to use. Visit http://www.dovepress.com/testimonials.php to read real quotes from published authors.

Submit your manuscript here: http://www.dovepress.com/oncotargets-and-therapy-journal 